Supporting information

\title{
Tailoring ligand environment towards development of colorimetric and fluorescence indicator for biological Mn(II) imaging
}

Susanta Adhikari, ${ }^{a^{*}}$ Avijit Ghosh ${ }^{\mathrm{a}}$, Animesh Sahana ${ }^{\mathrm{a}}$, Subhajit Guria ${ }^{\mathrm{a}}$ and Debasis $\operatorname{Das}^{\mathrm{b}}$

${ }^{a}$ Department of Chemistry, University of Calcutta, 92, A.P.C. Road, Kolkata 700 009, West Bengal, India.

E-mail address: adhikarisusanta@yahoo.com

* Tel.: +91 33 23509937; fax: +91 3323519755.

${ }^{b}$ Department of Chemistry, The University of Burdwan, Burdwan 713104, West Bengal, India. 


\section{INDEX}

General information

Detail synthetic procedure.

${ }^{1} \mathrm{H},{ }^{13} \mathrm{C}$ NMR Spectra and mass spectra of the compounds.

Figure S-18 Color changes of RDDB in acetonitrile solution upon gradual addition of $\mathrm{Mn}^{2+}$

Figure S-19 Plot of emission intensities of RDDBin presence of different cations

Figure S-20 Plot of emission intensities of RDDB in presence of different cations

Figure S-21 Expanded linear region of the plot (emission intensity vs. $\mathrm{Mn}^{2+}$ concentration) of RDDB $(10 \mu \mathrm{M})$ up to $10 \mu \mathrm{M}$ of $\mathrm{Mn}^{2+}$

Figure S-22 Absorbancevs. $\mathrm{Mn}^{2+}$ concentration of RDDB up to $10 \mu \mathrm{M}$ of $\mathrm{Mn}^{2+}$

Figure S-23 Plot of absorbance of RDDB in presence of different cations

Figure S-24 Effect of $\mathrm{pH}$ on the emission intensity of RDDB $(10 \mu \mathrm{M})$ and [RDDB- $-\mathbf{M n}^{2+}$ ] systems

Figure S-25 Job's plot (stoichiometry determination of the $\mathbf{R D D B}^{-\mathbf{M n}^{2+}}$ adduct) in acetonitrile

Figure S-26 Determination of the binding constant of RDDB with $\mathrm{Mn}^{2+}$ using the fluorescence technique 
Figure S-27 Color changes (naked eye and under UV-lamp) of RDDB in acetonitrile solution upon addition of different cations.

Figure S-28 Determination of the binding constant of FHDB with $\mathrm{Mn}^{2+}$ using the fluorescence technique.

Figure S-29 Job's plot (stoichiometry determination of the FHDB-Mn ${ }^{2+}$ adduct) in DMSO

Figure S-30 Plot of emission intensities of FHDB in presence of different cations

Figure S-31 Color changes of FHDB in DMSO solution upon gradual addition of $\mathrm{Mn}^{2+}$

Figure S-32 Effect of pH on the emission intensity of FHDB and [FHDB-Mn ${ }^{2+}$ ] systems in DMSO.

Figure S-33 Emission intensities of DFB in presence of different cations in DMSO nm

Figure S-34 Emission intensities of RDADB in presence of different cations in DMSO

Figure S-35 Emission intensities of DFFL in presence of different cations in DMSO nm)...(S30)

Figure S-36 Absorbance of DFFL in presence of different cations in DMSO.

Figure S-37 Relative absorbance of DFP, 2-aminobenzamidazole, rhodamine hydrazide and fluorescein hydrazide in presence of $\mathrm{Mn}^{2+}$ in

DMSO

Figure S-38 Relative emission intensities of DFP, 2-aminobenzamidazole, rhodamine hydrazide and fluorescein hydrazide in presence of $\mathrm{Mn}^{2+}$ in DMSO 
Table S-1 comparison of individual fluorescence unit and their metal ion binding properties

Table S-2 Comparison of the present probe with existing $\mathrm{Mn}^{2+}$ probes

Figure S-39 QTOF MASS spectrum of [RDDB-Mn $\left.{ }^{2+}\right]$ system.

Figure S-40 Expanded region of QTOF MASS spectrum of [RDDB-Mn $\left.{ }^{2+}\right]$ system

Figure S-41 FTIR complex of RDDB.

Figure S-42 Energy optimized geometry of RDDB.

Table S-3 Frontier molecular orbitals (MOs) of RDDB and the energy levels of the MOs.

Figure S-43 Energy optimized geometry of RDDB- $\mathrm{Mn}^{2+}$

Table S-4 The frontier molecular orbitals (MOs) of RDDB- $\mathrm{Mn}^{2+}$ and the energy levels of the MOs.

In vitro cell imaging.

Cytotoxicity assay

Figure S-44 Cell viability of RDDB

\section{General information:}

Chemicals and solvents were purchased from commercial suppliers and used as received. ${ }^{1} \mathrm{H}$ and ${ }^{13} \mathrm{C}$ NMR spectra were recorded on a Bruker Avance III HD (300 MHz) spectrometer. Chemical shifts were reported in parts per million (ppm), and the residual solvent peak was used as an internal reference: proton (chloroform $\delta$ 7.26), carbon (chloroform $\delta$ 77.16) or tetramethylsilane (TMS $\delta 0.00)$ was used as a reference. Multiplicity was indicated as follows: s (singlet), d (doublet), t (triplet), q (quartet), m (multiplet), dd (doublet of doublet), bs (broad 
singlet). Coupling constants were reported in Hertz $(\mathrm{Hz})$. High resolution mass spectra were obtained on a Micromass/Q-Toff. micro ${ }^{\mathrm{TM}}$ spectrometer. Melting points were determined on a Thomas Hoover capillary melting point apparatus. IR spectra were measured on Thermo Scientific Nicolet 380 instrument. For thin layer chromatography (TLC), Merck precoated TLC plates (Merck 60 F254) were used, and compounds were visualized with a UV light at $254 \mathrm{~nm}$. Further visualization was achieved by staining with iodine.

\section{Calculation for detection limit}

To determine the detection limit, fluorescence titration of RDDBwith $\mathrm{Mn}^{2+}$ was carried out by addingaliquots of micro molar concentration of $\mathrm{Mn}^{2+}$. From the concentration at which there was a sharpchange in the fluorescence intensity multiplied with the concentration of RDDBgive the detectionlimit.

\section{Equation used for calculating detection limit (DL)}

$\mathrm{DL}=\mathrm{CL} \times \mathrm{CT}$

$\mathrm{CL}=$ Conc. of ligand; $\mathrm{CT}=$ Conc. of $\mathrm{Mn}^{2+}$ at which fluorescence enhanced.

Thus;

$\mathrm{DL}=1 \times 10^{-6} \times 0.05 \times 10^{-6}=0.05 \times 10^{-6}$

Synthesis of (E)-3-(((1H-benzo[d]imidazol-2-yl)imino)methyl)-2-hydroxy-5methylbenzaldehyde (DFB)

$330 \mathrm{mg}$ of 2, 6-diformyl-p-cresol $(2.01 \mathrm{mmol})$ was taken in 9:1 dry acetonitrile: ethanol and then added drop wise $267.68 \mathrm{mg}$ of 2-aminomenzamidazole $(2.01 \mathrm{mmol})$ in dry acetonitrile for 1 hour in $\mathrm{Ar}$ atmosphere. The color of the solution changes from deep yellow to orange. The mixture was stirred at $40^{\circ} \mathrm{C}$ for overnight. After completion of the reaction confirmed by TLC, the orange crystalline solids were filtered and washed with $100 \mathrm{ml}$ of dry ether, dried in vacuum to obtained 
$500 \mathrm{mg}$ of DFCas orange solid (yield $88 \%$ ). $\mathrm{R}_{\mathrm{f}^{-}} 0.35$ in $40 \%$ ethyl acetate-petroleum ether. The target product was confirmed by ${ }^{1} \mathrm{H}$ NMR (Figure S1) (300 MHz, DMSO-d 6 ): 10.04 (s, 1H), 9.45 (s, 4H), $7.43(\mathrm{~m}, 1 \mathrm{H}), 7.02-7.09(\mathrm{~m}, 2 \mathrm{H}), 6.81(\mathrm{~m}, 1 \mathrm{H}), 2.17(\mathrm{~s}, 3 \mathrm{H}) ;{ }^{13} \mathrm{C}$ NMR (Figure S2) $(75$ MHz, DMSO-d $\left.{ }_{6}\right) \delta 192.45,165.65,161.81,140.05,137.51,136.77,133.88,128.98,124.65$, 123.76, 122.88, 120.84, 115.53, 20.03. QTOF MASS (Figure S3) m/z $(\mathrm{M}+\mathrm{H})^{+}$calculated. For $\mathrm{C}_{16} \mathrm{H}_{14} \mathrm{~N}_{3} \mathrm{O}_{2}^{+}: 280.10860$, found: 280.1086 .

\section{Synthesis of 2-(((E)-3-((E)-((1H-benzo[d]imidazol-2-yl)imino)methyl)-2-hydroxy-5- methylbenzylidene)amino)-3',6'-dihydroxyspiro[isoindoline-1,9'-xanthen]-3-one ( FHDB)}

$300 \mathrm{mg}$ of DFB $(1.07 \mathrm{mmol})$ and $371 \mathrm{mg}$ of fluorescein hydrazide $(1.07 \mathrm{mmol})$ were taken in dry ethanol in Ar atmosphere and refluxed for $16 \mathrm{~h}$. After completion of the reaction confirmed by TLC, the red crystalline solids were filtered and washed with $100 \mathrm{ml}$ of dry ether and cold methanol, dried the in vacuum to obtained $520 \mathrm{mg}$ of FHDB as Brown red solid (yield $80 \%$ ). $\mathrm{R}_{\mathrm{f}^{-}}$ 0.5 in 4\% MeOH-DCM. ${ }^{1} \mathrm{H}$ NMR (Figure S4) (300 MHz, DMSO-d 6 ): $\delta 9.99$ (s, 1H), 9.12(s, 1H), 8.05(s, 1H), 7.92(m, 2H), 7.78(m, 2H), 7.55-7.68(m, 3H), 7.13(m, 2H), 6.65(m, 2H), 6.426.52(m, 4H), 2.064(s, 3H) ${ }^{13} \mathrm{C}$ NMR (Figure S5) (75 MHz, DMSO-d $\left.\mathrm{d}_{6}\right) \delta 163.47,161.27,159.47$, 152.07, 151.59, 146.28, 139.97, 135.20, 134.28, 129.62, 128.49, 127.46, 126.59, 124.06, 124.06, 123.73, 115.58, 113.34, 108.29, 102.77, 64.66, 22.11; QTOF MASS (Figure S6) m/z (M+H) calculated. For $\mathrm{C}_{36} \mathrm{H}_{26} \mathrm{~N}_{5} \mathrm{O}_{5}^{+}$: 608.19339, found: 608.1933 .

\section{Synthesis of 2-(((E)-3-((E)-((1H-benzo[d]imidazol-2-yl)imino)methyl)-2-hydroxy-5- methylbenzylidene)amino)-3',6'-bis(diethylamino)spiro[isoindoline-1,9'-xanthen]-3-one (RDDB)}

$300 \mathrm{mg}$ of DFB $(1.07 \mathrm{mmol})$ and $488.52 \mathrm{mg}$ of rhodamine hydrazide $(1.07 \mathrm{mmol})$ were taken in dry ethanol in Ar atmosphere and refluxed for $12 \mathrm{~h}$. After completion of the reaction confirmed 
by TLC, the red crystalline solids were filtered and washed with $100 \mathrm{ml}$ of dry ether and cold methanol, dried the in vacuum to obtained $650 \mathrm{mg}$ of RDDBas Brown yellow solid (yield 84\%). $\mathrm{R}_{\mathrm{f}}-0.5$ in $2 \% \mathrm{MeOH}-\mathrm{DCM} .{ }^{1} \mathrm{H}$ NMR (Figure S7) $\left(300 \mathrm{MHz}, \mathrm{CDCl}_{3}\right): \delta 8.89(\mathrm{~s}, 1 \mathrm{H}), 8.62(\mathrm{~s}$, 1H), 7.97(m, 2H), 7.42-7.52 (m, 2H), 7.01-7.14 (m, 2H), 6.96(m, 2H), 6.77(m, 2H), 6.45-6.51(m, $4 \mathrm{H}), 6.19-6.27(\mathrm{~m}, 2 \mathrm{H}), 3.30(\mathrm{~m}, 8 \mathrm{H}), \quad 2.09(\mathrm{~s}, 3 \mathrm{H}), 1.13(\mathrm{~m}, 12 \mathrm{H}) ;{ }^{13} \mathrm{C}$ NMR (Figure $\left.\mathrm{S} 8\right)(75$ $\left.\mathrm{MHz}, \mathrm{CDCl}_{3}\right) \delta 163.89,153.99,152.91,152.69 .151 .48,150.88,148.68,138.57,133.13,132.87$, $130.34,128.11,127.66,123.36,122.93,117.54,107.86,105.11,104.74,97.82,61.54,43.94$, 19.79, 12.09; QTOF MASS (Figure S9) $\mathrm{m} / \mathrm{z}(\mathrm{M}+\mathrm{H})^{+}$calculated. For $\mathrm{C}_{44} \mathrm{H}_{44} \mathrm{~N}_{7} \mathrm{O}_{3}{ }^{+}: 718.35056$, found: 718.3505 .

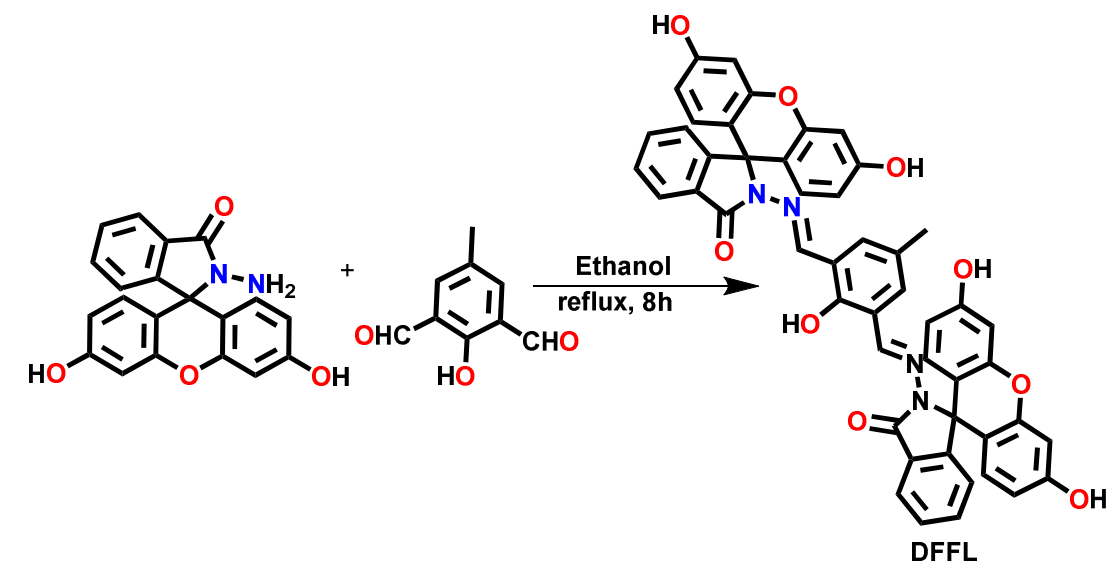

\section{SchemeS-1.Synthetic scheme of DFFL.}

Synthesis of 2,2"-(((1E,1'E)-(2-hydroxy-5-methyl-1,3-phenylene)bis(methanylylidene)) bis(azanylylidene))bis(3',6'-dihydroxyspiro[isoindoline-1,9'-xanthen]-3-one) (DFFL)

$330 \mathrm{mg}$ of 2, 6-diformyl-p-cresol $(2.01 \mathrm{mmol})$ and $1392.24 \mathrm{mg}$ of fluorescein hydrazide (4.02 $\mathrm{mmol})$ were taken in dry ethanol in Ar atmosphere and refluxed for $18 \mathrm{~h}$. After completion of the reaction confirmed by TLC, the deep yellow crystalline solids were filtered and washed with $100 \mathrm{ml}$ of dry ether and cold methanol, dried the in vacuum to obtained $1500 \mathrm{mg}$ of DFFLas Brown yellow solid (yield 90\%). $\mathrm{R}_{\mathrm{f}}-0.5$ in $10 \% \mathrm{MeOH}-\mathrm{DCM} .{ }^{1} \mathrm{H}$ NMR (Figure $\left.\mathrm{S} 10\right)(300$ 
MHz, DMSO-d $\left.\mathrm{d}_{6}\right): \delta 10.13(\mathrm{~s}, 1 \mathrm{H}), 8.92(\mathrm{~s}, 2 \mathrm{H}), 7.92(\mathrm{~m}, 2 \mathrm{H}), 7.56(\mathrm{~m}, 2 \mathrm{H}), 7.45(\mathrm{~m}, 2 \mathrm{H})$, 7.12(m, 4H), 6.83(m, 4H), 6.42-6.52(m, 8H), 2.17(s, 3H); ${ }^{13} \mathrm{C}$ NMR (Figure S11) (75 MHz, $\left.\mathrm{CDCl}_{3}\right) \delta 164.03,159.15,152.50,151.32,147.14,134.66,130.81,129.56,128.71,128.26$ 124.13, 123.70, 112.94, 109.65, 103.20, 65.42, 20.18; QTOF MASS (Figure S12) m/z (M+H) calculated. For $\mathrm{C}_{49} \mathrm{H}_{33} \mathrm{~N}_{4} \mathrm{O}_{9}^{+}$: 821.22475, found: 821.2247.

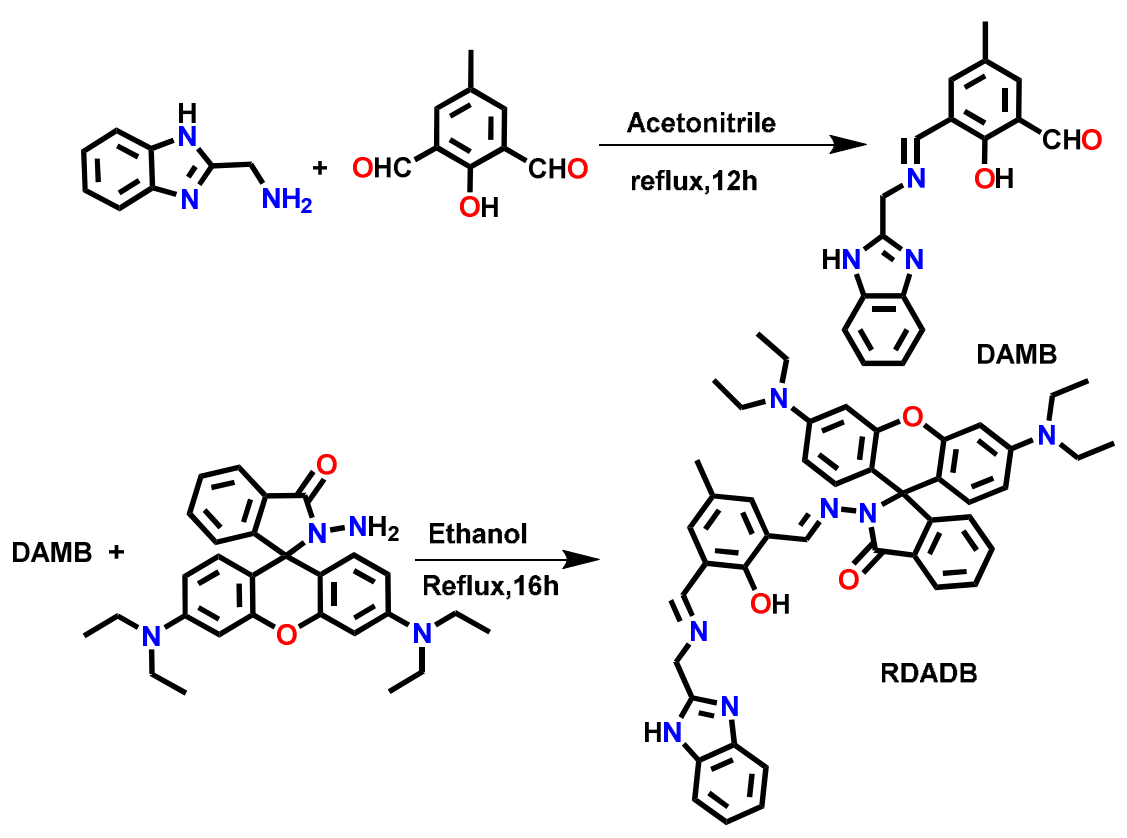

Scheme S-2. Syntheticscheme of model compound RDADB.

Synthesis of (E)-3-((((1H-benzo[d]imidazol-2-yl)methyl)imino)methyl)-2-hydroxy-5methylbenzaldehyde (DAMB)

$330 \mathrm{mg}$ of 2, 6-diformyl-p-cresol $(2.01 \mathrm{mmol})$ was taken in 9:1 dry acetonitrile: ethanol and then $295.81 \mathrm{mg}$ of 2-aminomethyl benzamidazole $(2.01 \mathrm{mmol})$ added drop wise in dry acetonitrile for 1 hour in Ar atmosphere. The color of the solution changes from deep yellow to orange. The mixture was stirred at $40{ }^{\circ} \mathrm{C}$ for overnight. After completion of the reaction confirmed by TLC, the light orange crystalline solids were filtered and washed with $100 \mathrm{ml}$ of dry ether, dried in vacuum to obtained $500 \mathrm{mg}$ of DAMBas light orange solid (yield $84 \%$ ). $\mathrm{R}_{\mathrm{f}^{-}} 0.40$ in $40 \%$ ethyl 
acetate-petroleum ether. The target product was confirmed by ${ }^{1} \mathrm{H}$ NMR (Figure S13) (300 MHz, $\left.\mathrm{CDCl}_{3}\right): \delta 9.77(\mathrm{~s}, 1 \mathrm{H}), 9.45(\mathrm{~m}, 1 \mathrm{H}), 7.62(\mathrm{~m}, 1 \mathrm{H}), 7.42-7.62(\mathrm{~m}, 2 \mathrm{H}), 7.12(\mathrm{~m}, 1 \mathrm{H}), 7.09(\mathrm{~m}$, 2H), 4.68(s, 2H), 2.17(s, 3H). QTOF MASS (Figure S14) $\mathrm{m} / \mathrm{z}(\mathrm{M}+\mathrm{H})^{+}$calculated. For $\mathrm{C}_{17} \mathrm{H}_{16} \mathrm{~N}_{3} \mathrm{O}_{2}^{+}: 294.12425$, found: 294.1242 .

\section{Synthesis of 2-(((E)-3-((E)-(((1H-benzo[d]imidazol-2-yl)methyl)imino)methyl)-2-hydroxy- 5-methylbenzylidene)amino)-3',6'-bis(diethylamino)spiro[isoindoline-1,9'-xanthen]-3-one (RDADB)}

$300 \mathrm{mg}$ of DAMB (1.02mmol) and $467.57 \mathrm{mg}$ of rhodamine hydrazide (1.02mmol) were taken in dry ethanol in Ar atmosphere and refluxed for $12 \mathrm{~h}$. After completion of the reaction confirmed by TLC, the red crystalline solids were filtered and washed with $100 \mathrm{ml}$ of dry ether and cold methanol, dried in the vacuum to obtained $650 \mathrm{mg}$ of RDDBas Brown yellow solid (yield 87\%). $\mathrm{R}_{\mathrm{f}^{-}} 0.4$ in $2 \% \mathrm{MeOH}-\mathrm{DCM} .{ }^{1} \mathrm{H}$ NMR (Figure S15) (300 MHz, DMSO-d $\mathrm{d}_{6}$ ): $\delta 10.17$ (s, 1H), $8.91(\mathrm{~s}, 1 \mathrm{H}), 8.78(1,2 \mathrm{H}), 7.88-7.94(\mathrm{~m}, 2 \mathrm{H}), 7.55-7.69(\mathrm{~m}, 2 \mathrm{H}), 7.39-7.48(\mathrm{~m}, 2 \mathrm{H})$, 7.02-7.12(m, 4H), 6.88(m, 2H), 6.29-6.44(m, 4H), 4.684(s, $1 \mathrm{H}), 3.30(\mathrm{~m}, 8 \mathrm{H}), \quad 2.18(\mathrm{~s}, 3 \mathrm{H})$, $1.07(\mathrm{~m}, 12 \mathrm{H}) ;{ }^{13} \mathrm{C}$ NMR (Figure S16) $\left(75 \mathrm{MHz}, \mathrm{CDCl}_{3}\right) \delta 168.15,160.99,158.91,153.62$. $148.92,144.46,141.89,141.01,137.97,132.55,132.39,128.93,128.77,126.58,125.61,108.22$ 105.54, 97.82, 59.73, 51.03, 44.41, 20.70, 12.70; QTOF MASS (Figure S17) m/z $(\mathrm{M}+\mathrm{H})^{+}$ calculated. For $\mathrm{C}_{45} \mathrm{H}_{46} \mathrm{~N}_{7} \mathrm{O}_{3}{ }^{+}$: 732.36621, found: 732.3662 . 


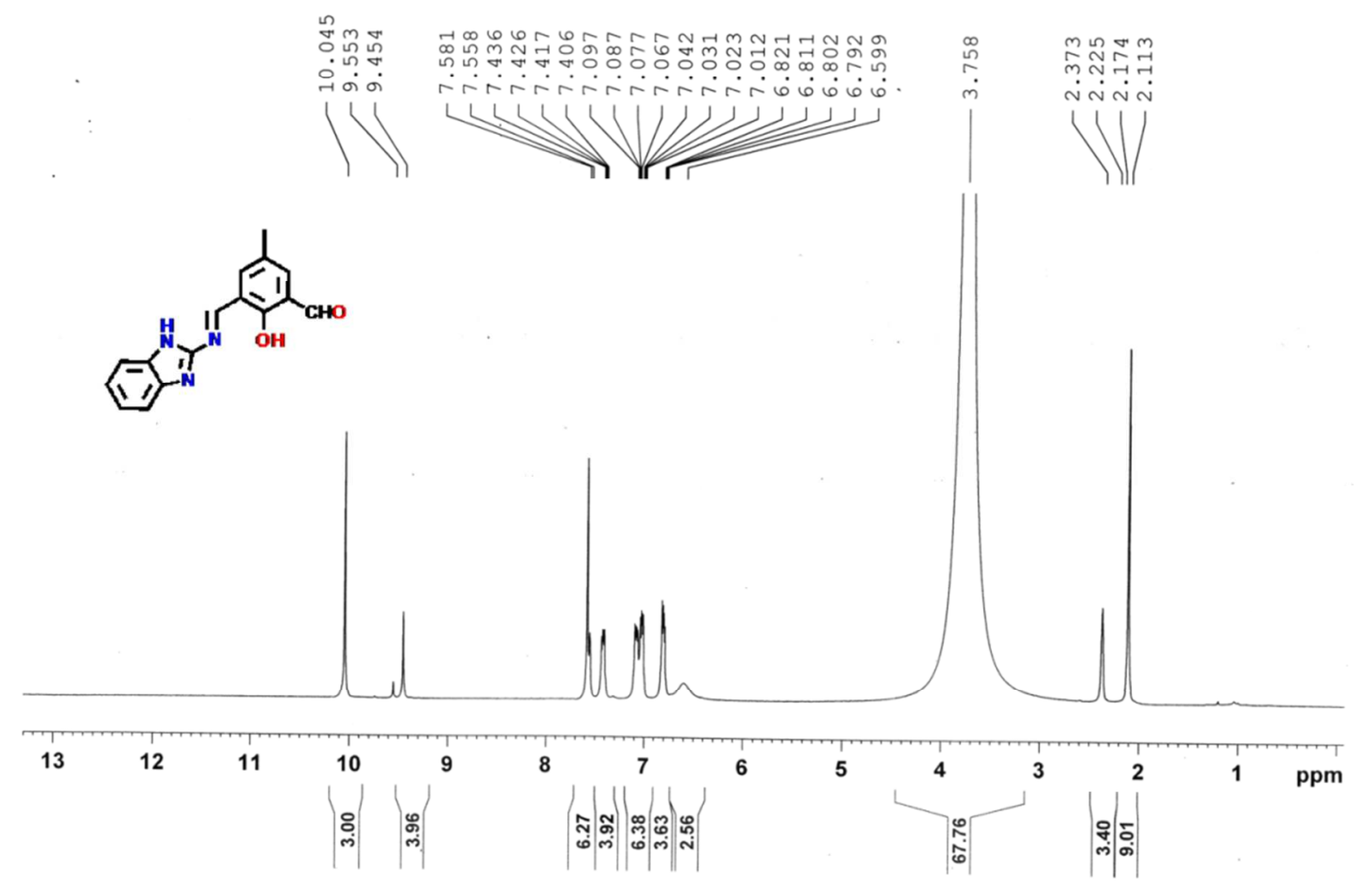

Figure S-1 ${ }^{1} \mathrm{H}$ NMR spectrum of DFB
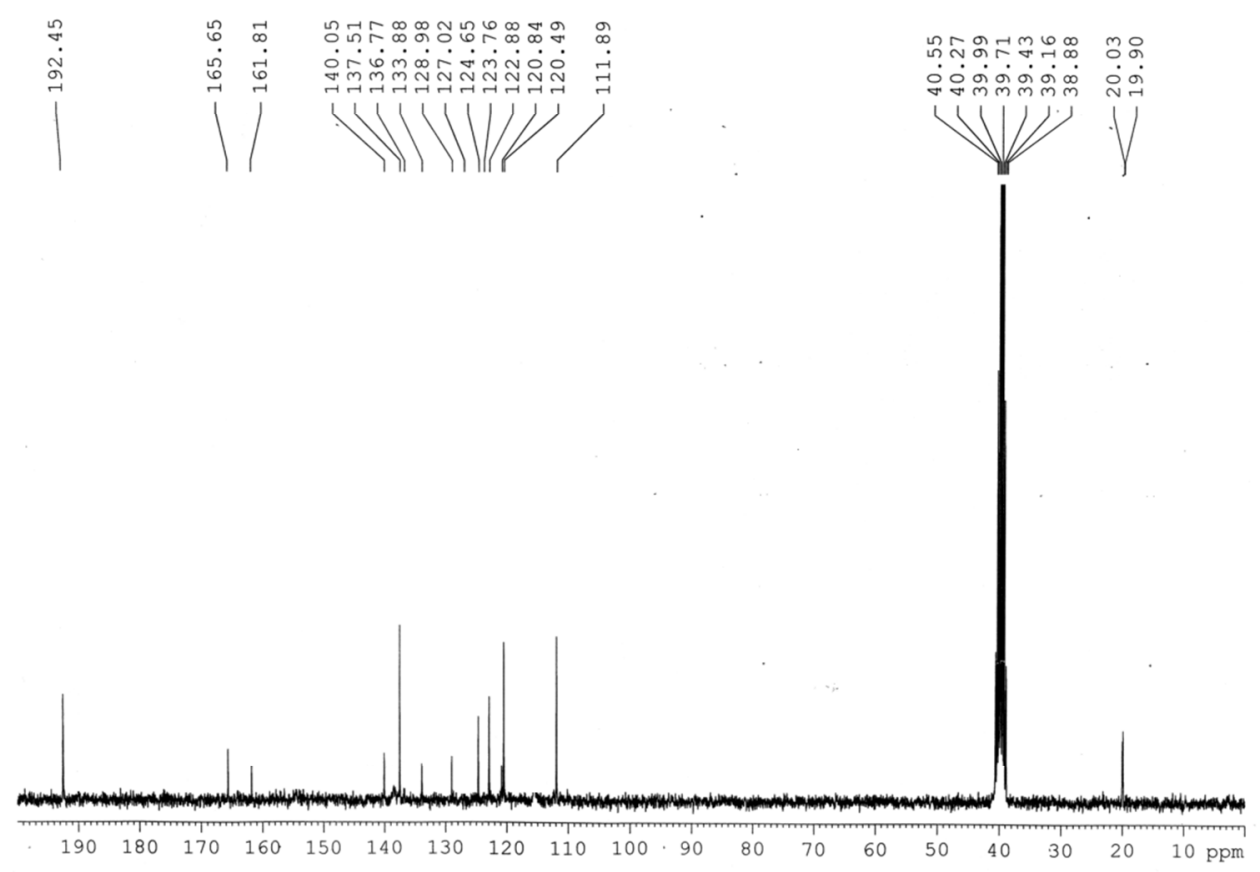
Figure S-2 ${ }^{13} \mathrm{C}$ NMR spectrum of DFB

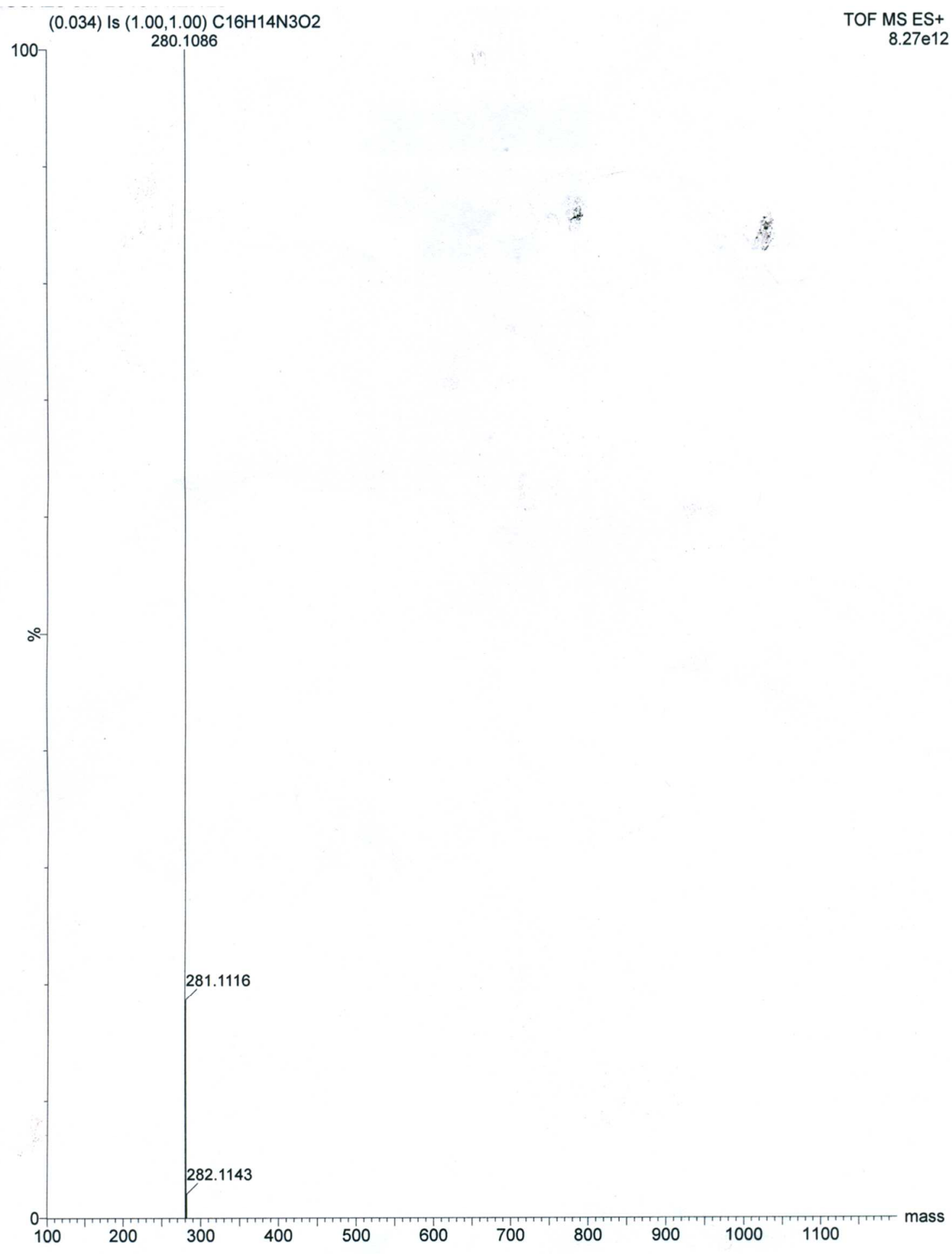

Figure S-3 QTOF MASS spectrum of DFB 


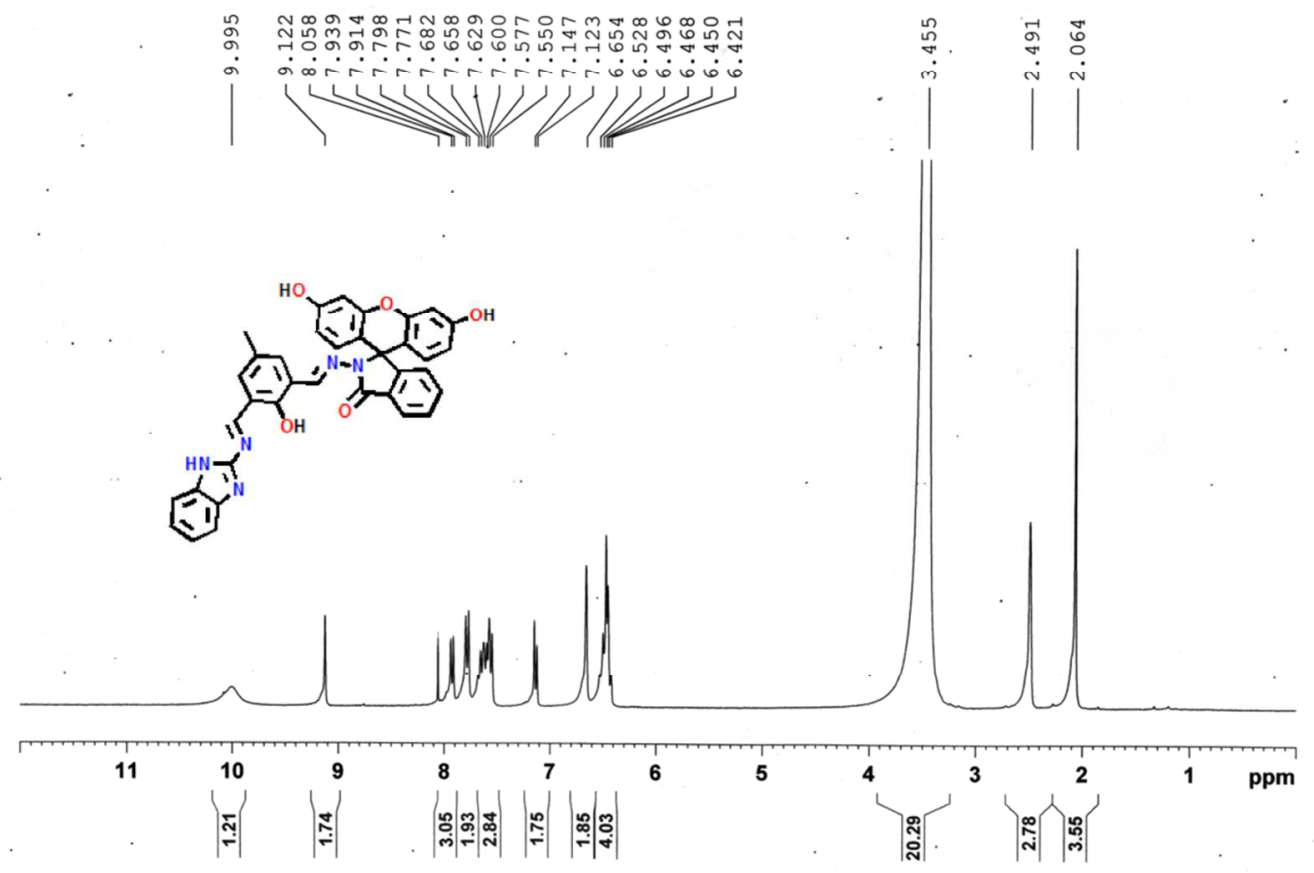

Figure S-4 ${ }^{1}$ H NMR spectrum of FHDB

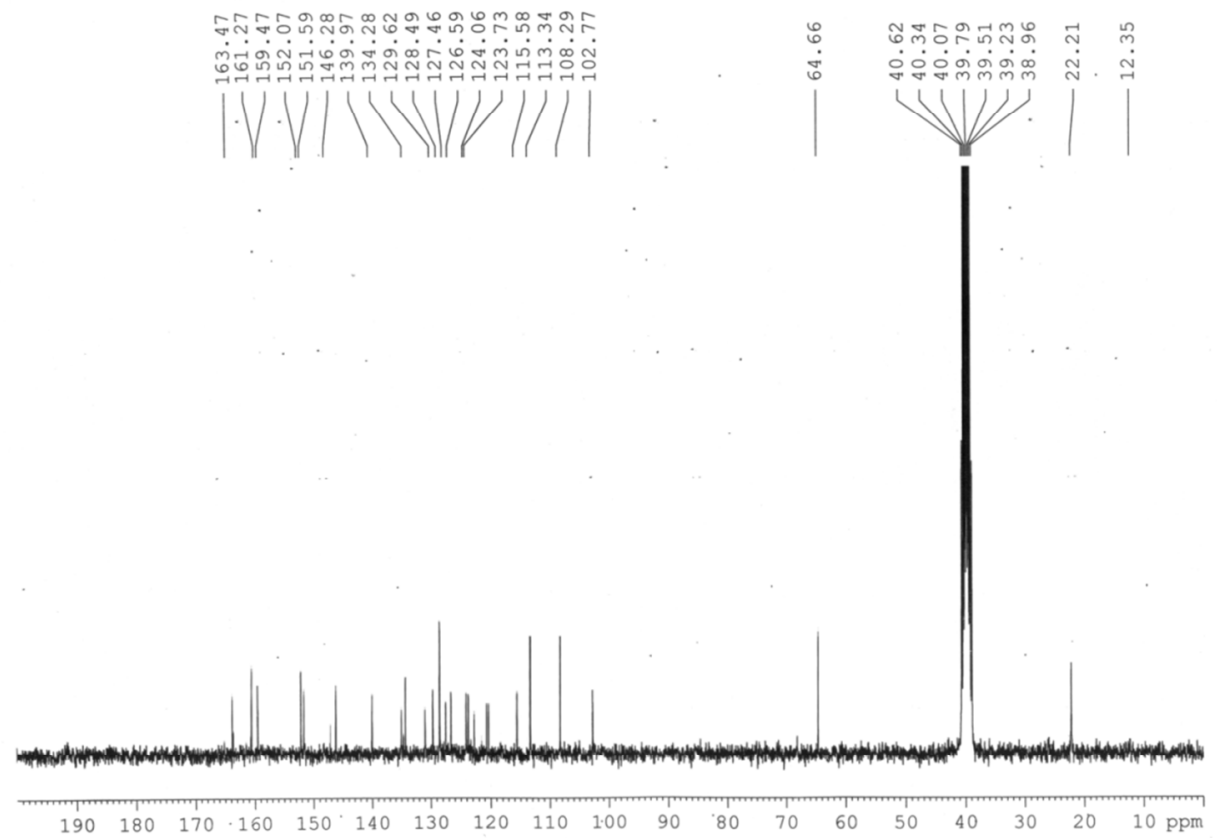

Figure S-5 ${ }^{13} \mathrm{C}$ NMR spectrum of FHDB 


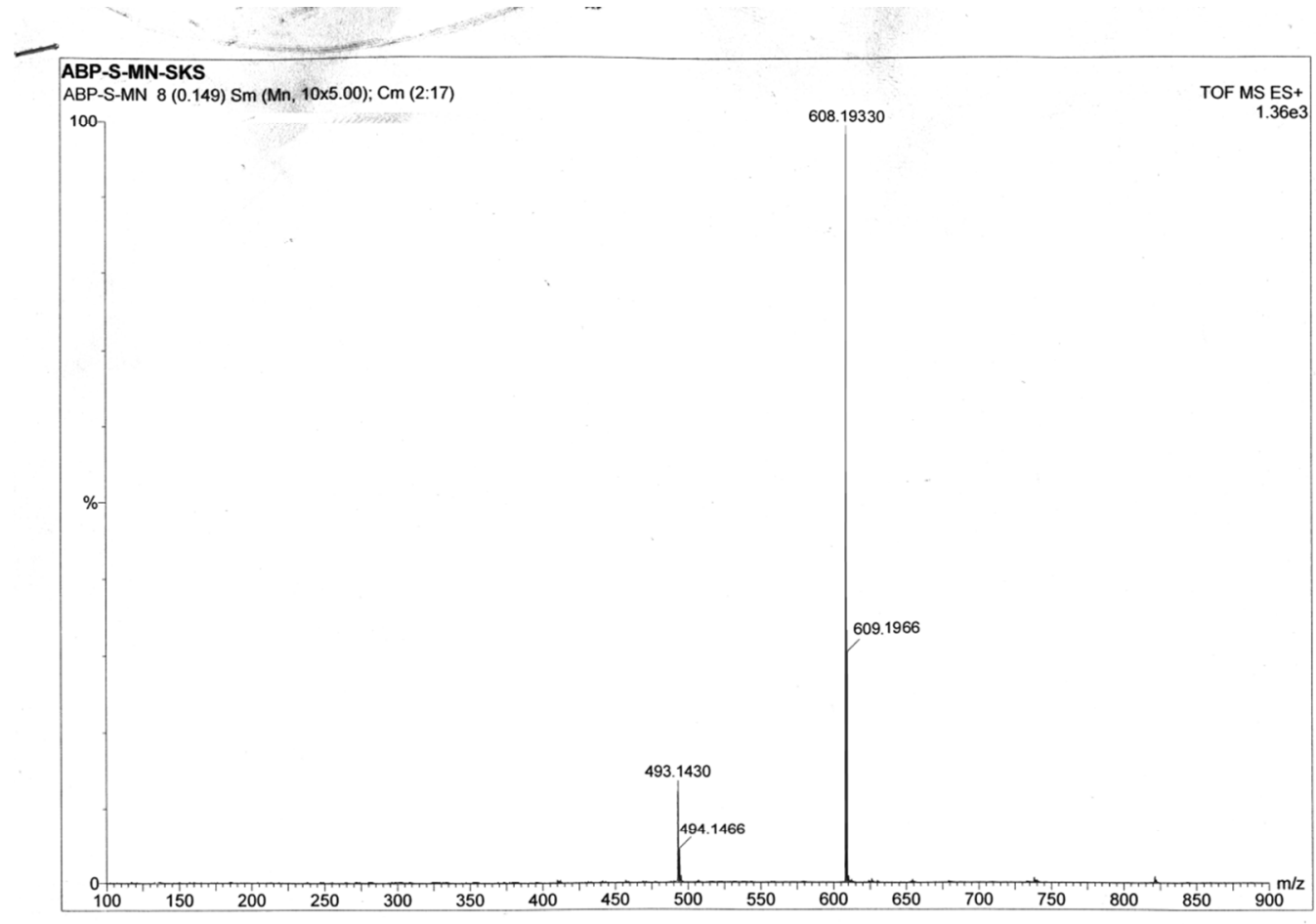

Figure S-6 QTOF MASS spectrum of FHDB

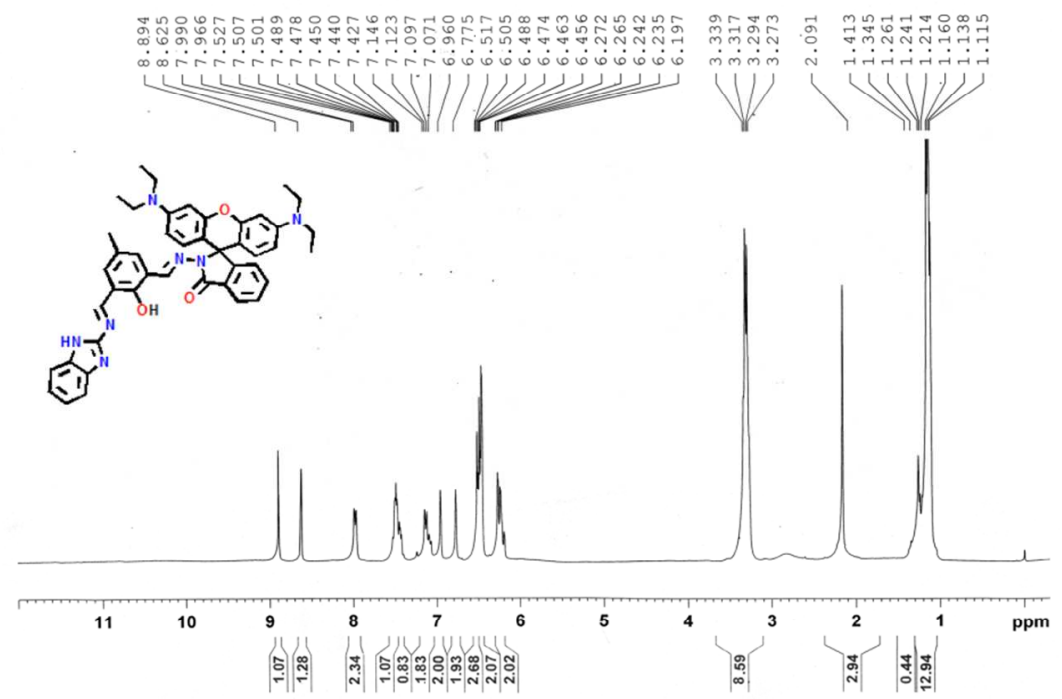

Figure S- ${ }^{1} \mathrm{H}$ NMR spectrum of RDDB 

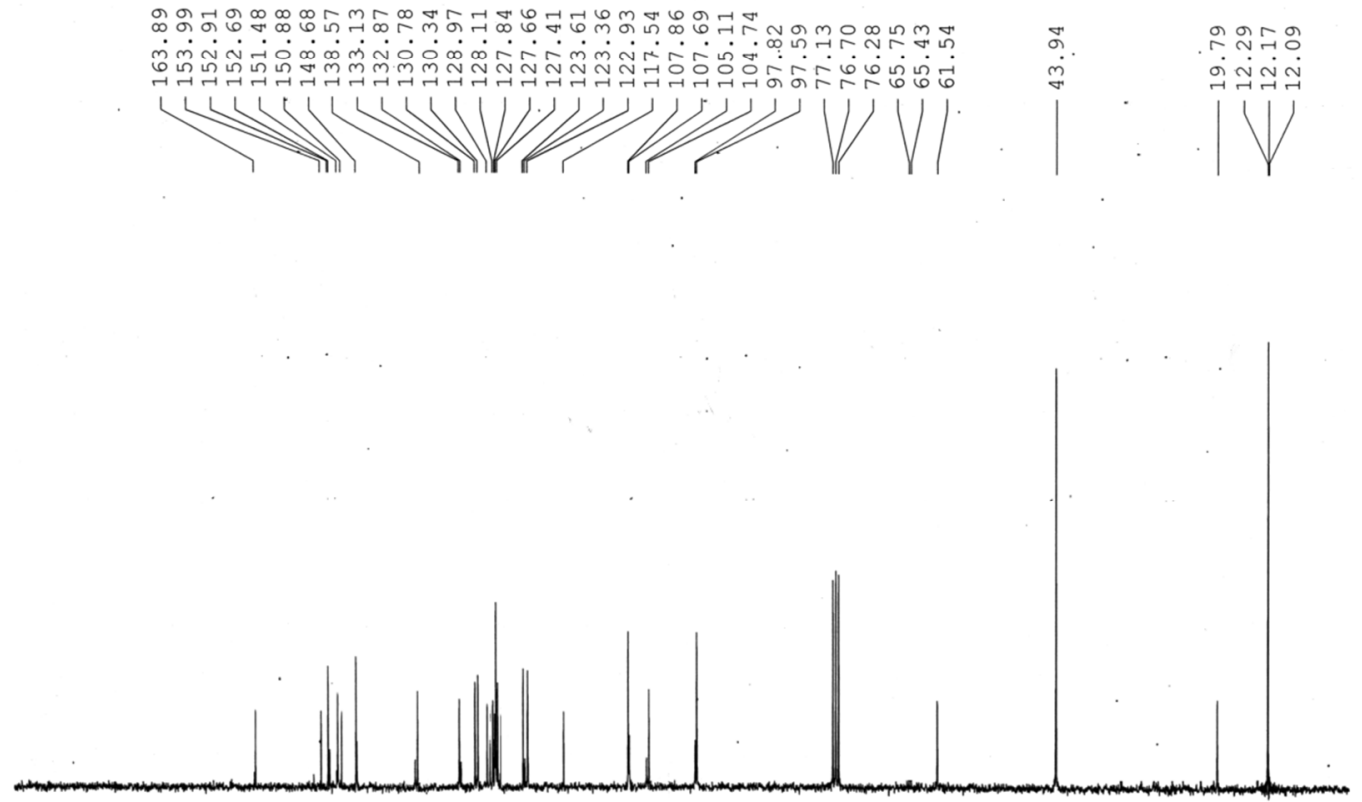

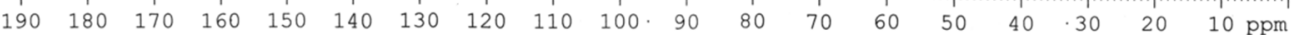

Figure $\mathbf{S - 8}{ }^{13} \mathrm{C}$ NMR spectrum of RDDB 


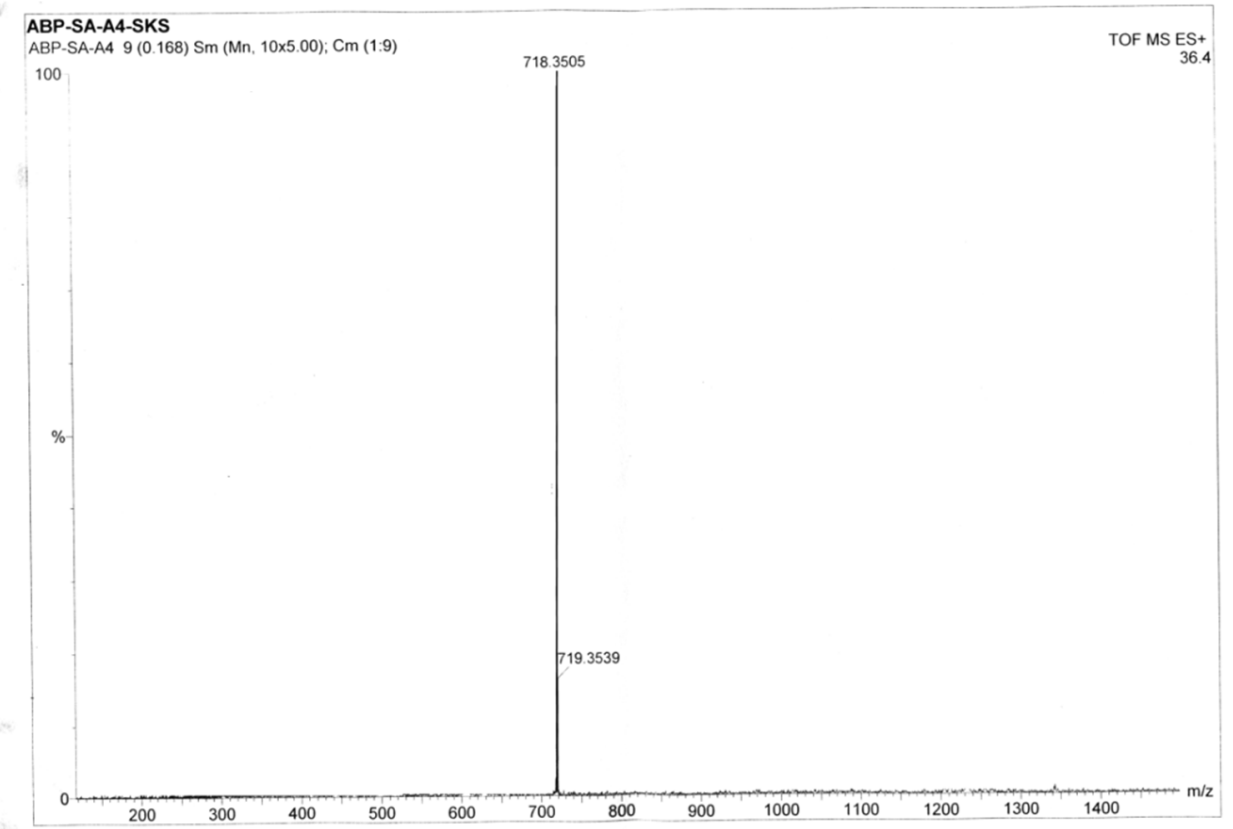

Figure S-9 QTOF MASS spectrum of RDDB

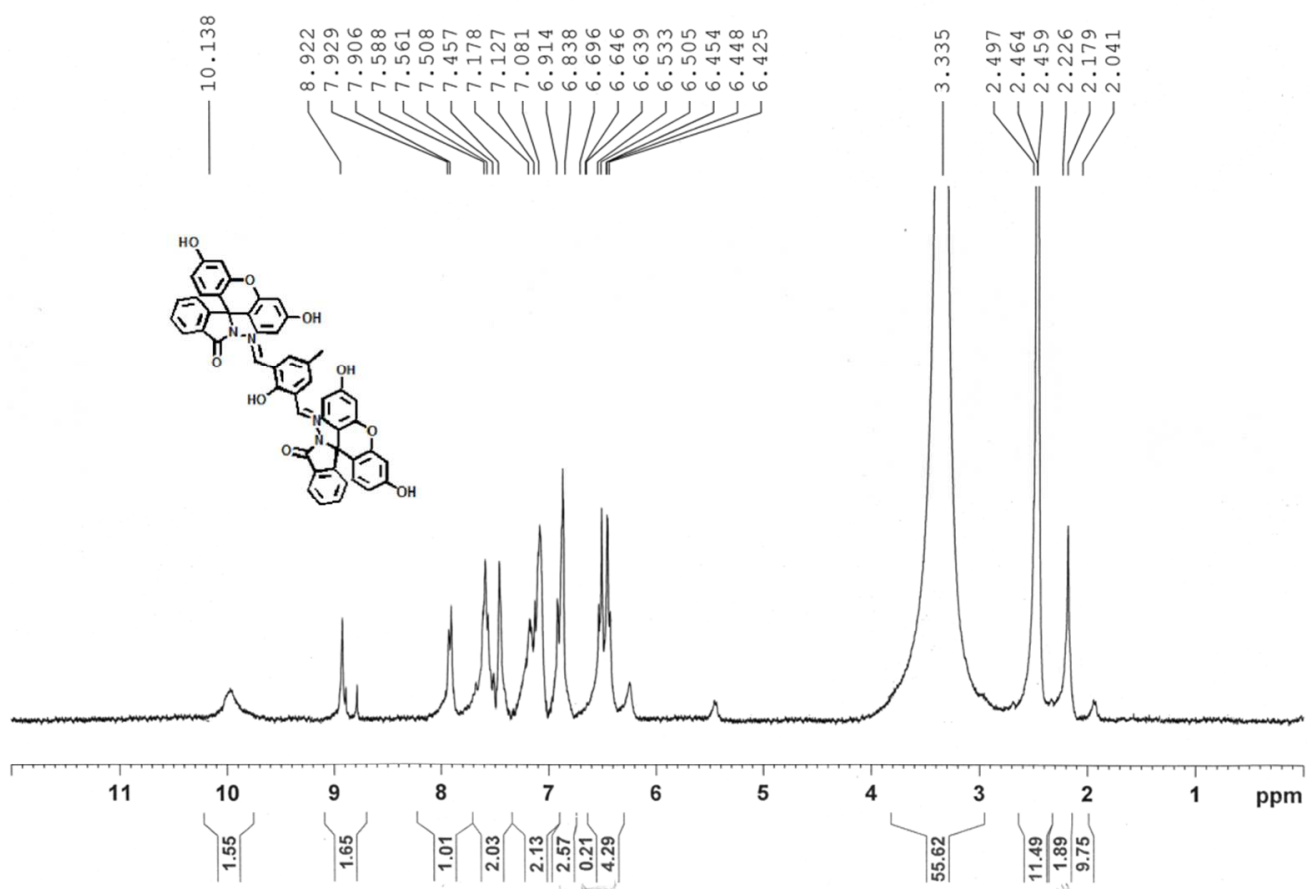

Figure S-10 ${ }^{1} \mathrm{H}$ NMR spectrum of DFFL 


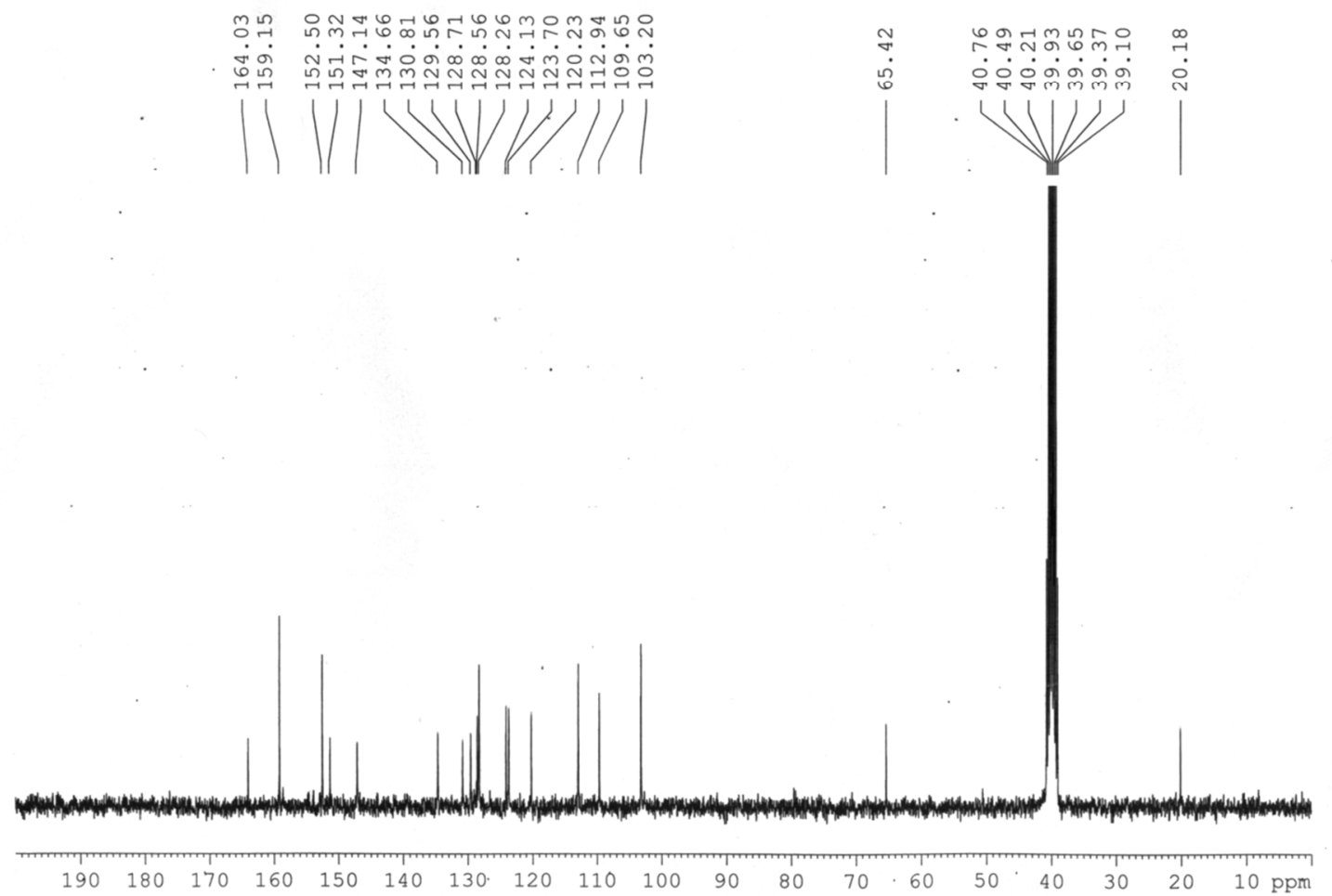

Figure $\mathbf{S - 1 1}{ }^{13} \mathrm{C}$ NMR spectrum of DFFL 


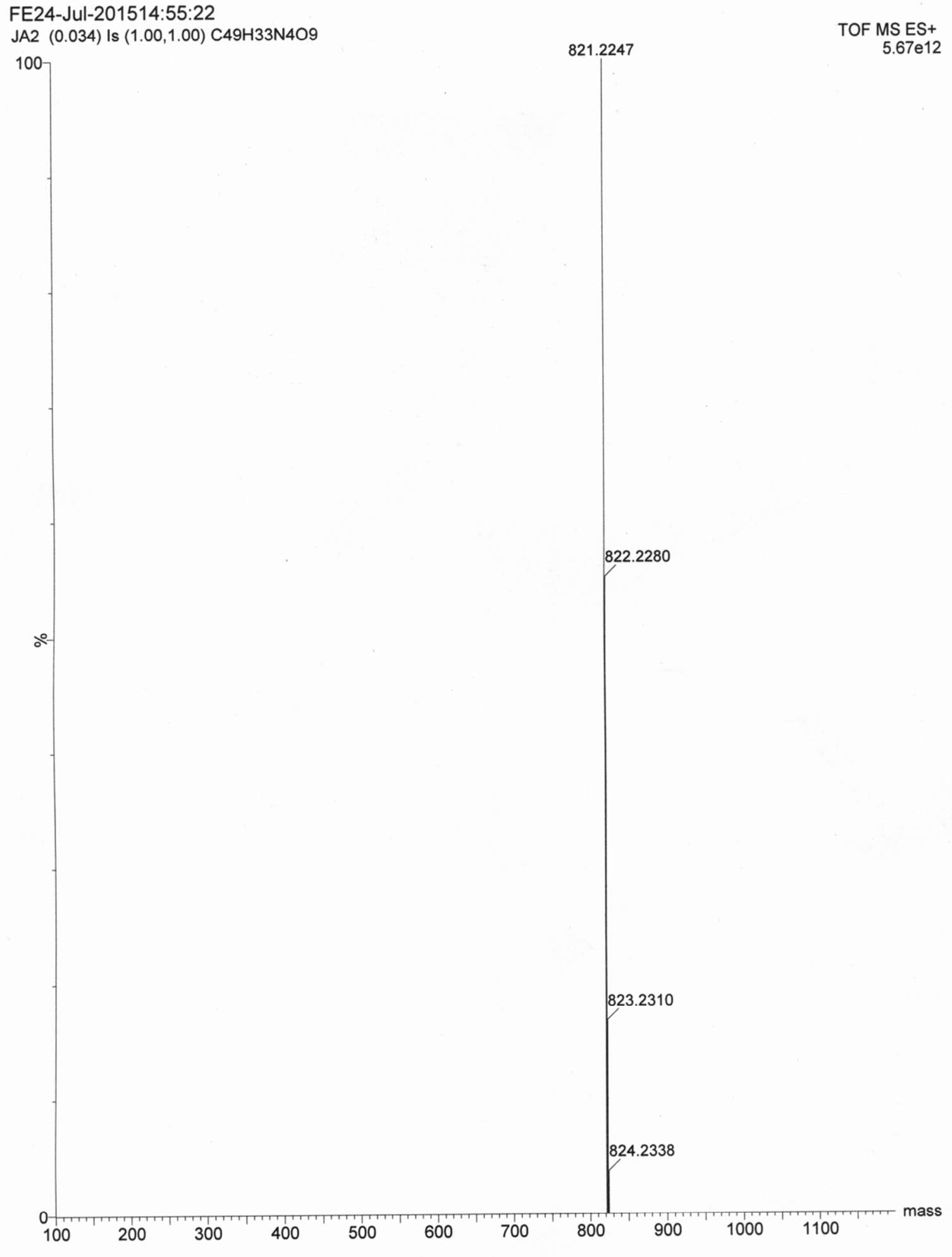

Figure S-12 QTOF MASS spectrum DFFL 

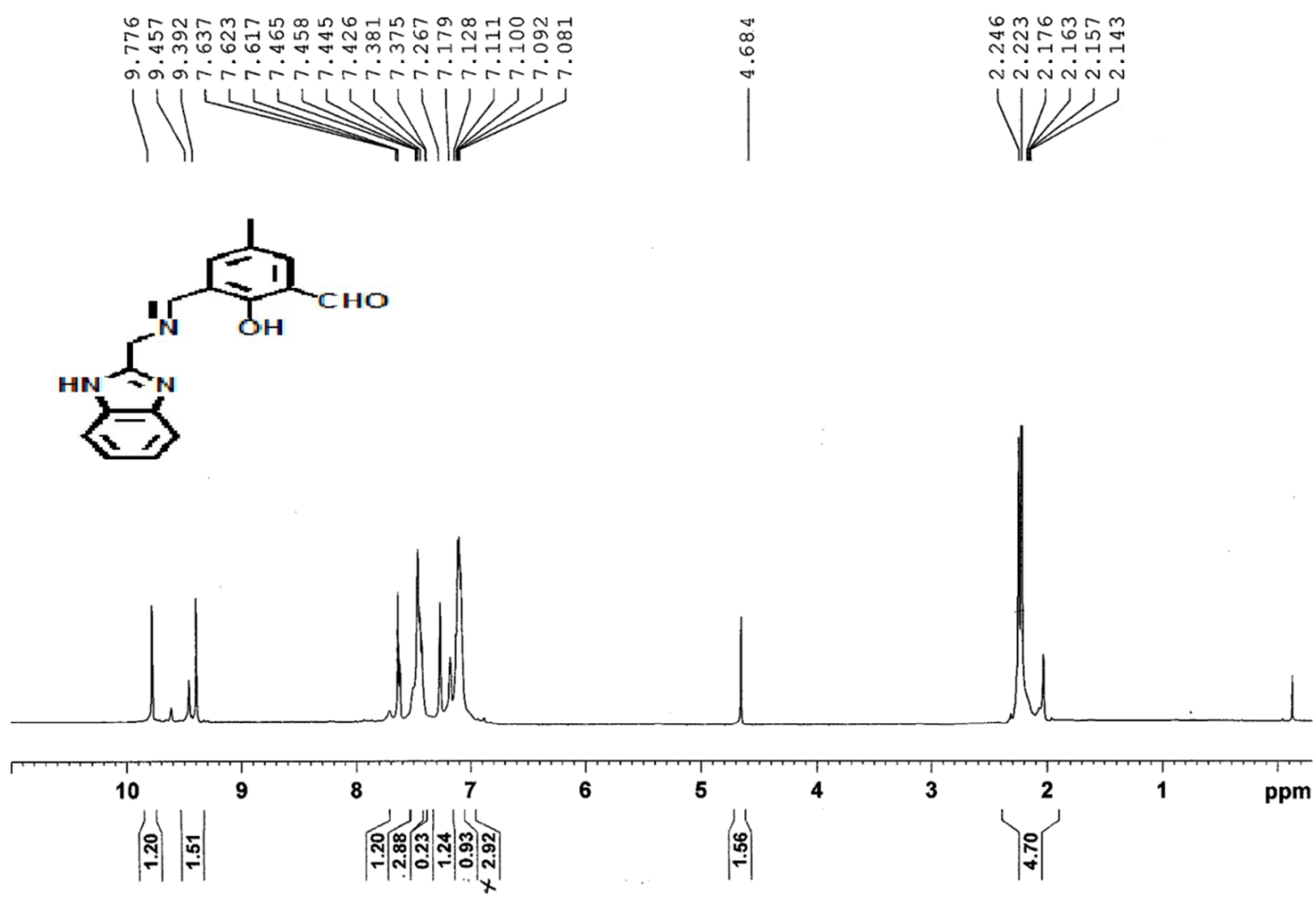

Figure S-13 ${ }^{1} \mathrm{H}$ NMR spectrum of DAMB 


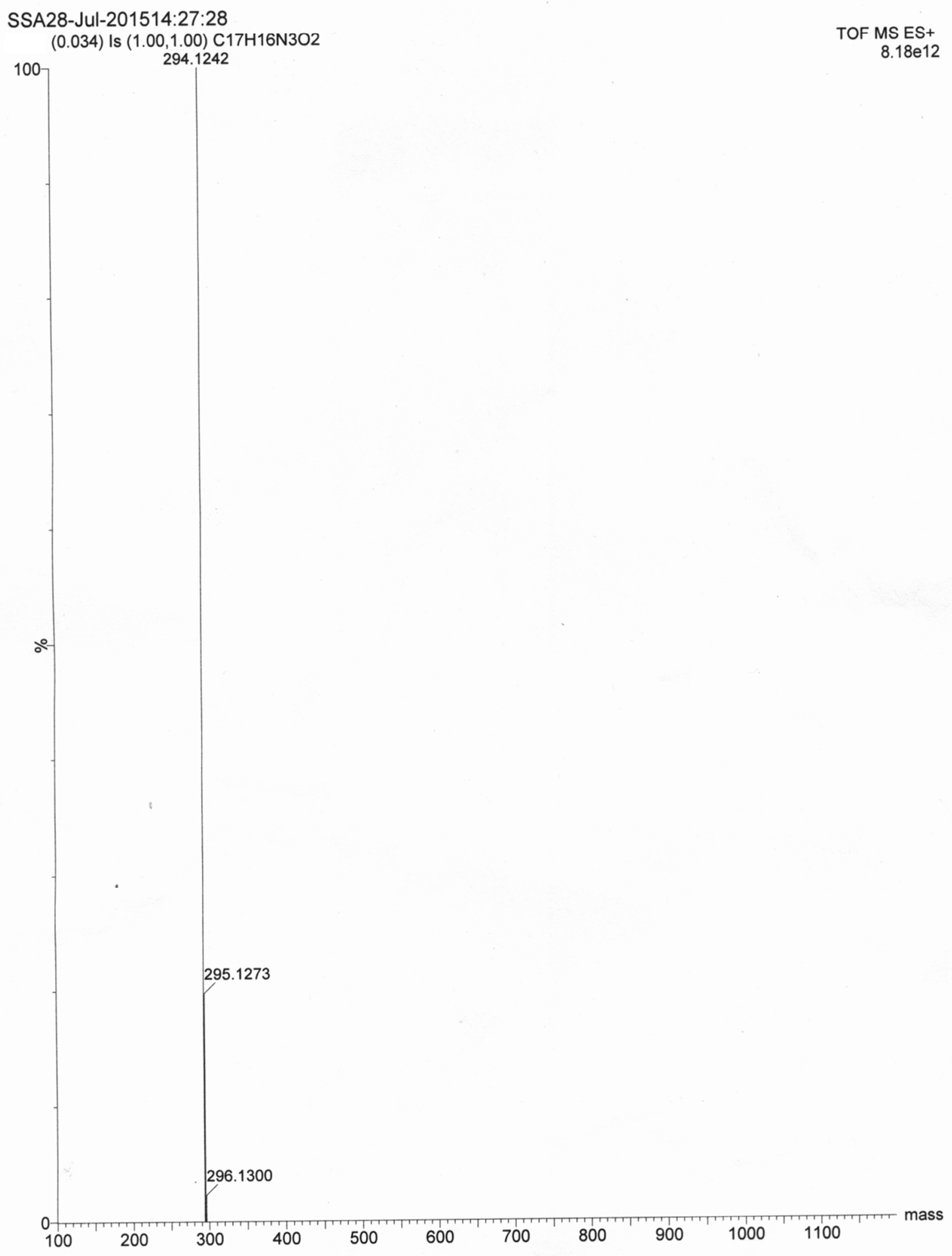

Figure S-14QTOF MASS spectrum DAMB 


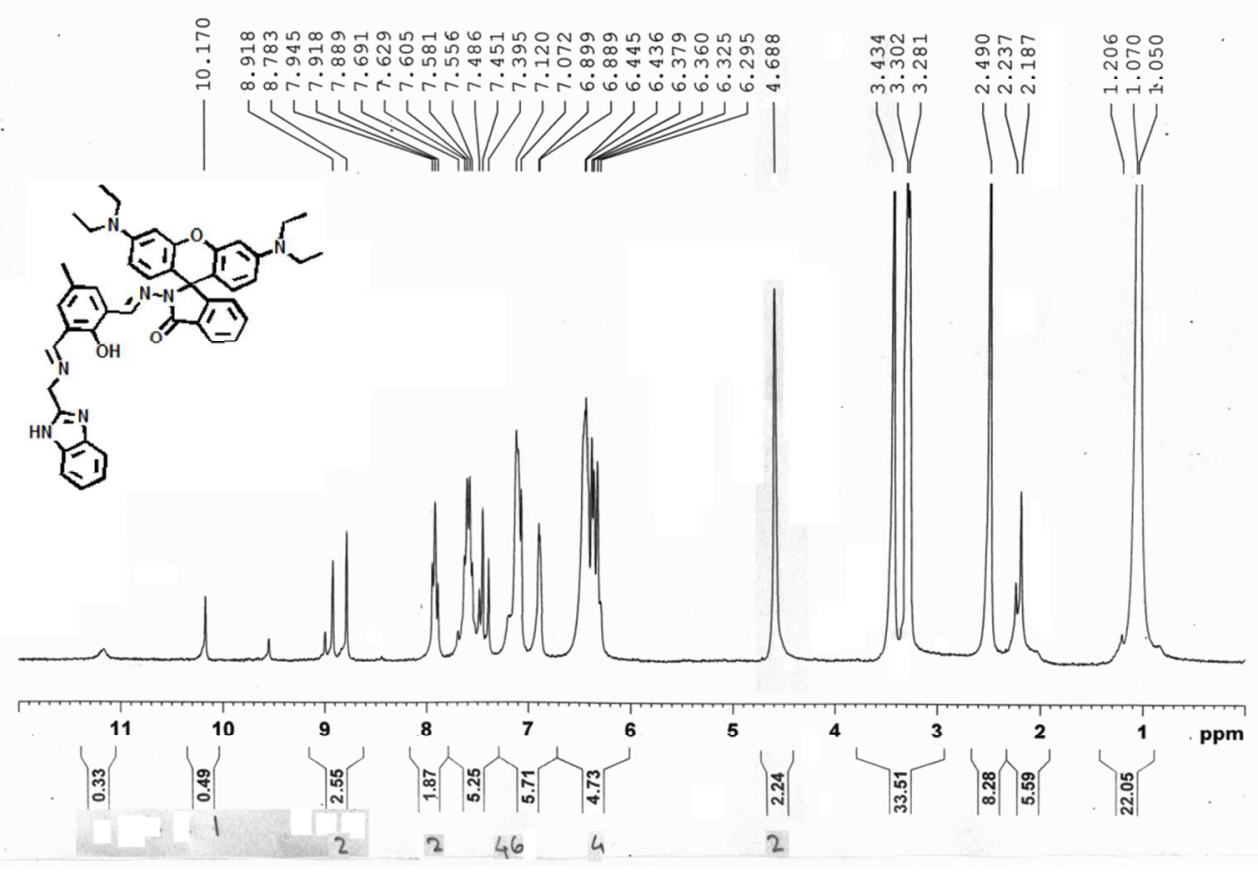

Figure $\mathbf{S - 1 5}{ }^{1} \mathrm{H}$ NMR spectrum of RDADB
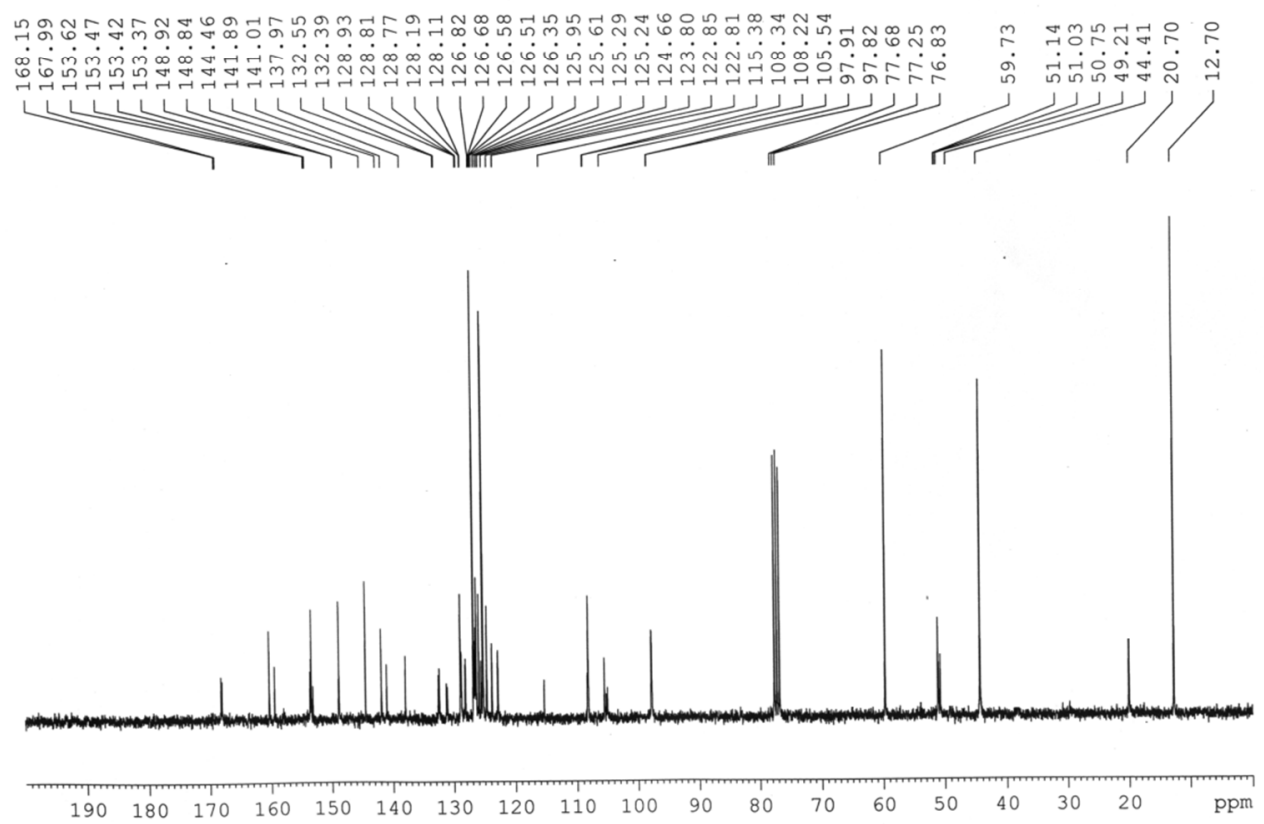

Figure S-16 ${ }^{13} \mathrm{C}$ NMR spectrum of RDADB 
SSA28-Jul-201514:59:23

$(0.034)$ Is $(1.00,1.00) \mathrm{C} 45 \mathrm{H} 46 \mathrm{~N} 7 \mathrm{O} 3$

732.3662

TOF MS ES+

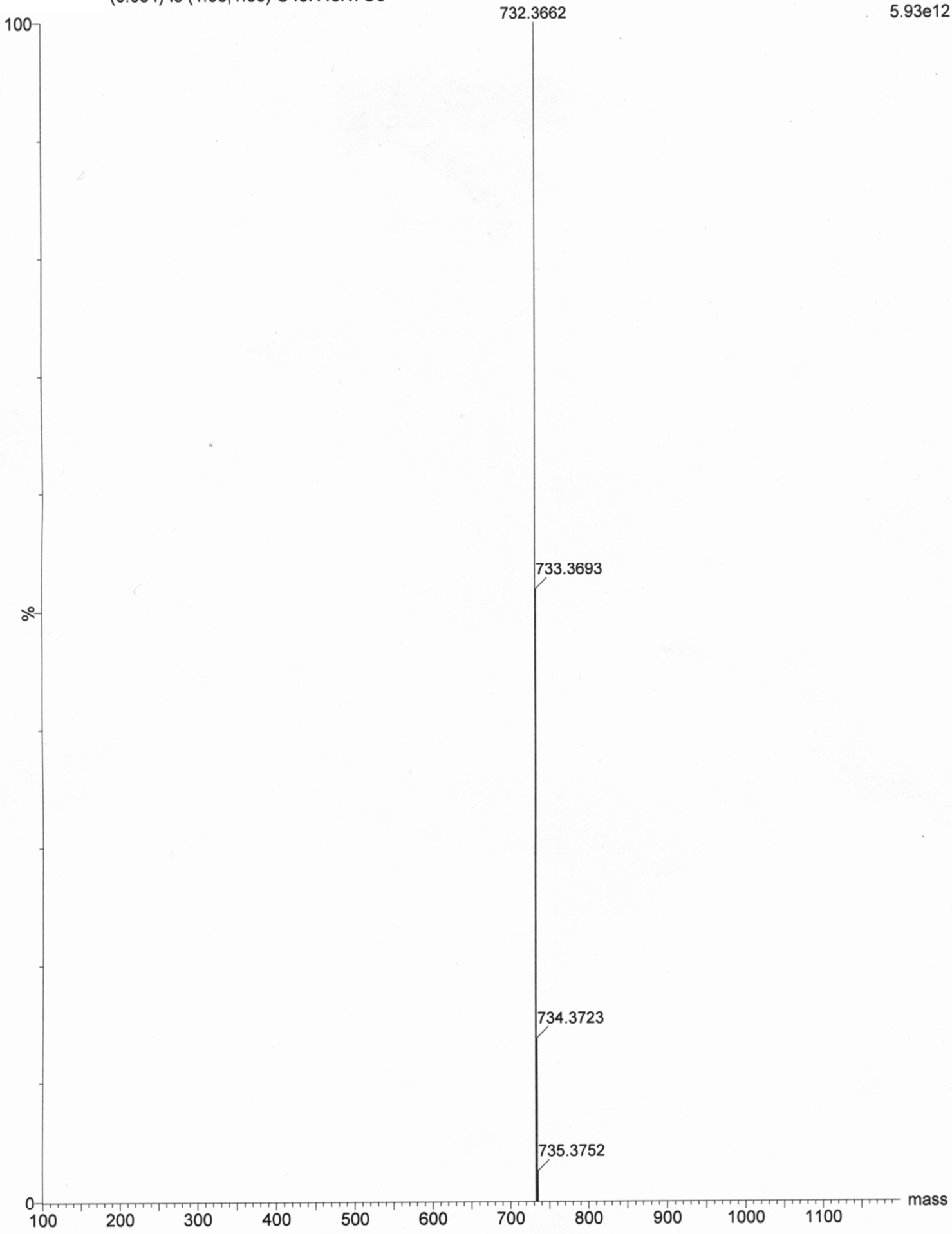

Figure S-17QTOF MASS spectrum RDADB 

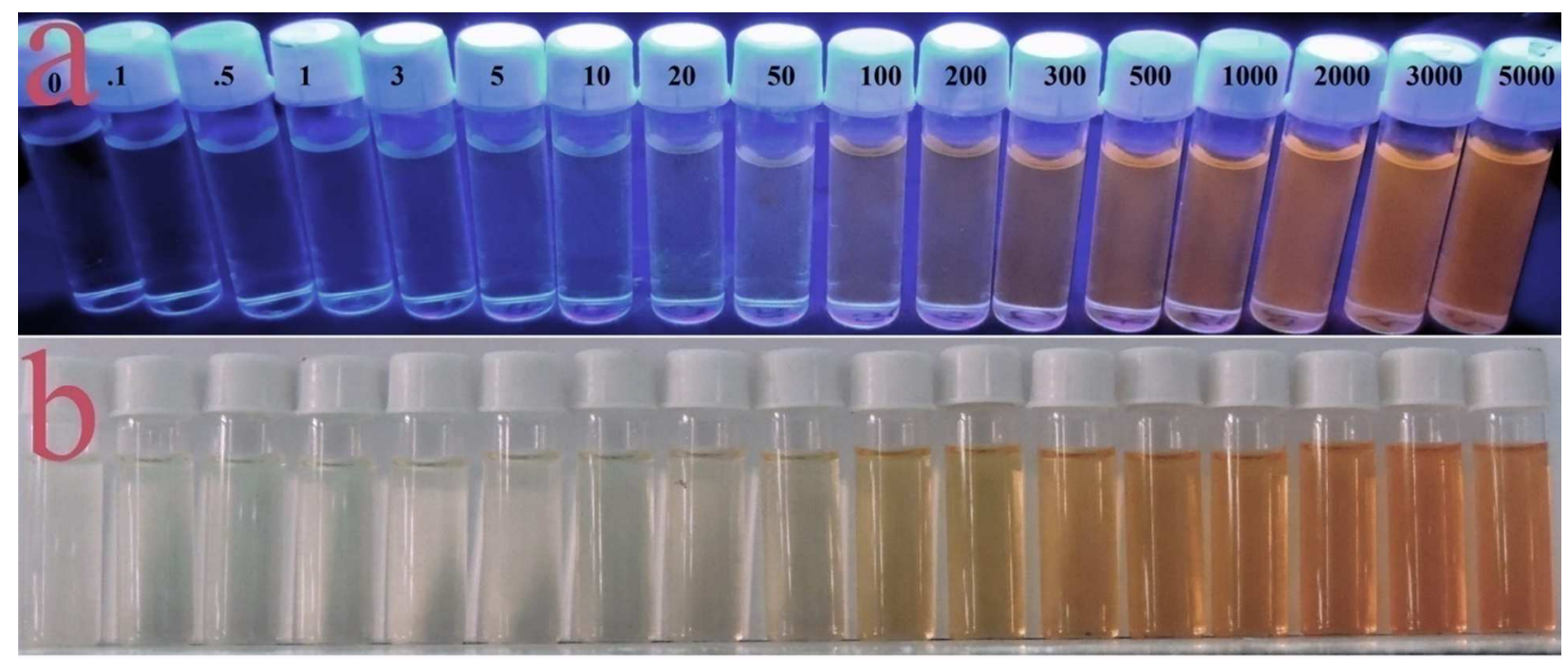

Figure S-18Color changes of RDDB $(10 \mu \mathrm{M})$ in acetonitrile solution upon gradual addition of $\mathrm{Mn}^{2+}(0.0$ to $500.0 \mu \mathrm{M})$ (a) under a hand held UV lamp and (b) in visible light necked eye color change.

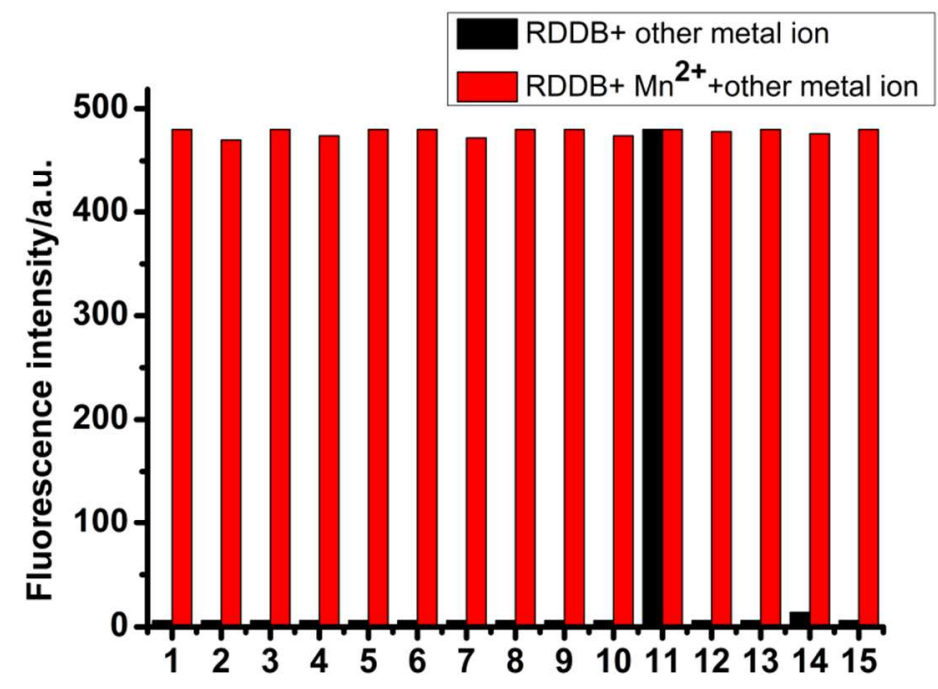

Figure S-19Plot of emission intensities of RDDB $(10 \mu \mathrm{M})$ in presence of different cations: $\mathrm{Zn}^{2+}$
(1) $\mathrm{Hg}^{2+}$
(2), $\mathrm{Ni}^{2+}(3), \mathrm{Pb}^{2+}$
(4), $\mathrm{Ca}^{2+}$
(5), $\mathrm{Ag}^{+}(6), \mathrm{Au}^{+}(7), \mathrm{Co}^{2+}$
$(8), \mathrm{Fe}^{3+}(9), \mathrm{Mg}^{2+}(10), \mathrm{Mn}^{2+}$
(11), $\mathrm{Cu}^{2+}(12), \mathrm{Cd}^{2+}(13), \mathrm{Cr}^{3+}(14)$ and $\mathrm{Al}^{3+}(15)$. 


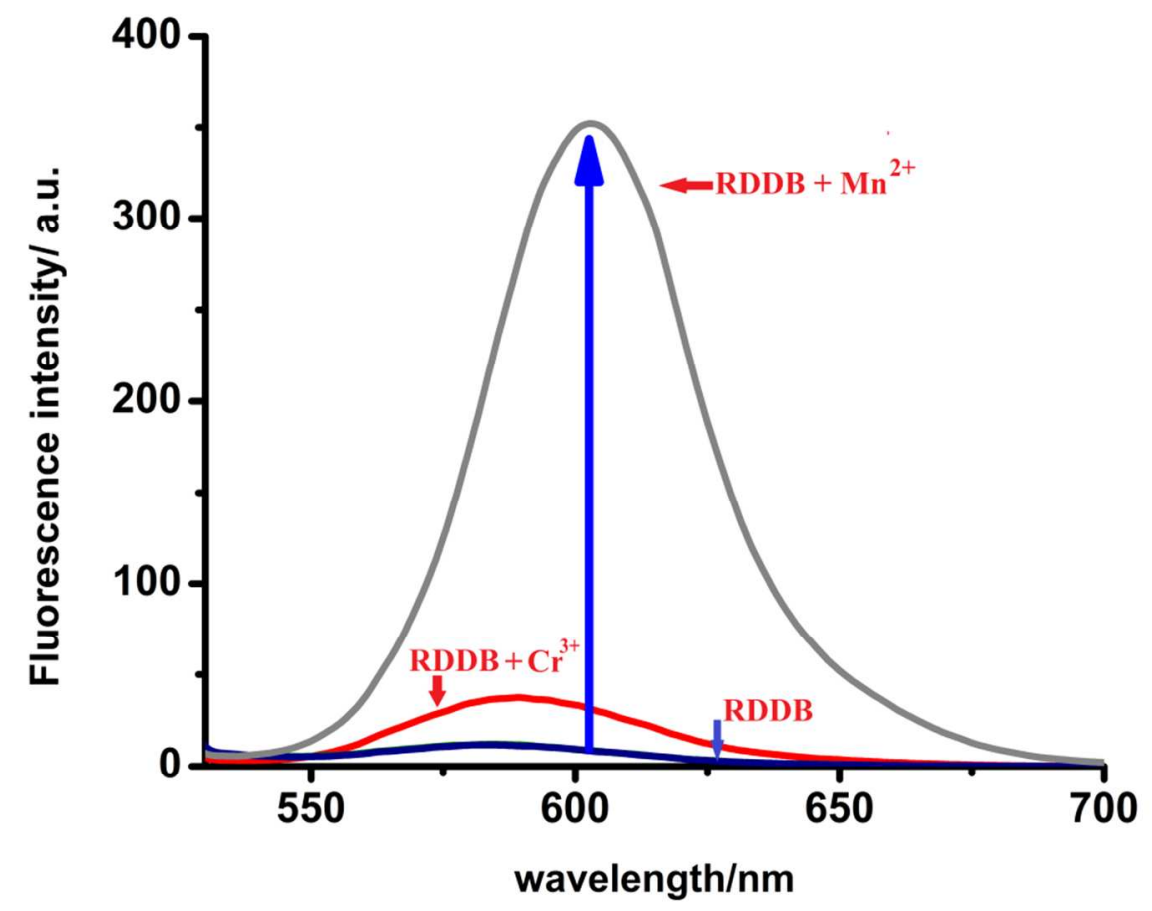

Figure S-20 Plot of emission intensities of RDDB $(10 \mu \mathrm{M})$ in presence of different cations in acetonitrile $\left(\lambda_{\mathrm{ex}}=520 \mathrm{~nm}\right)$.

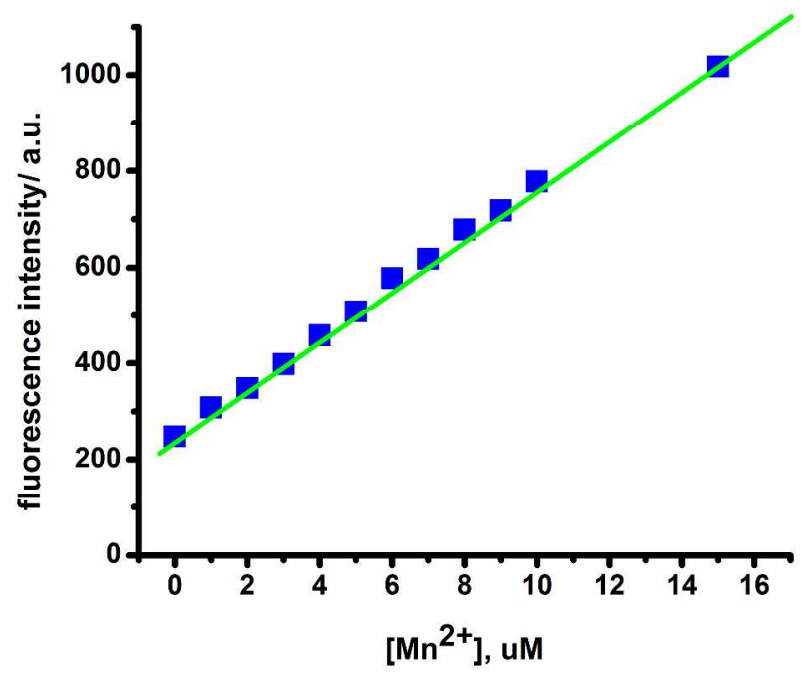

Figure S-21The expanded linear region of the plot (emission intensity $v s . \mathrm{Mn}^{2+}$ concentration) of RDDB $(10 \mu \mathrm{M})$ up to $10 \mu \mathrm{M}$ of $\mathrm{Mn}^{2+}$. 


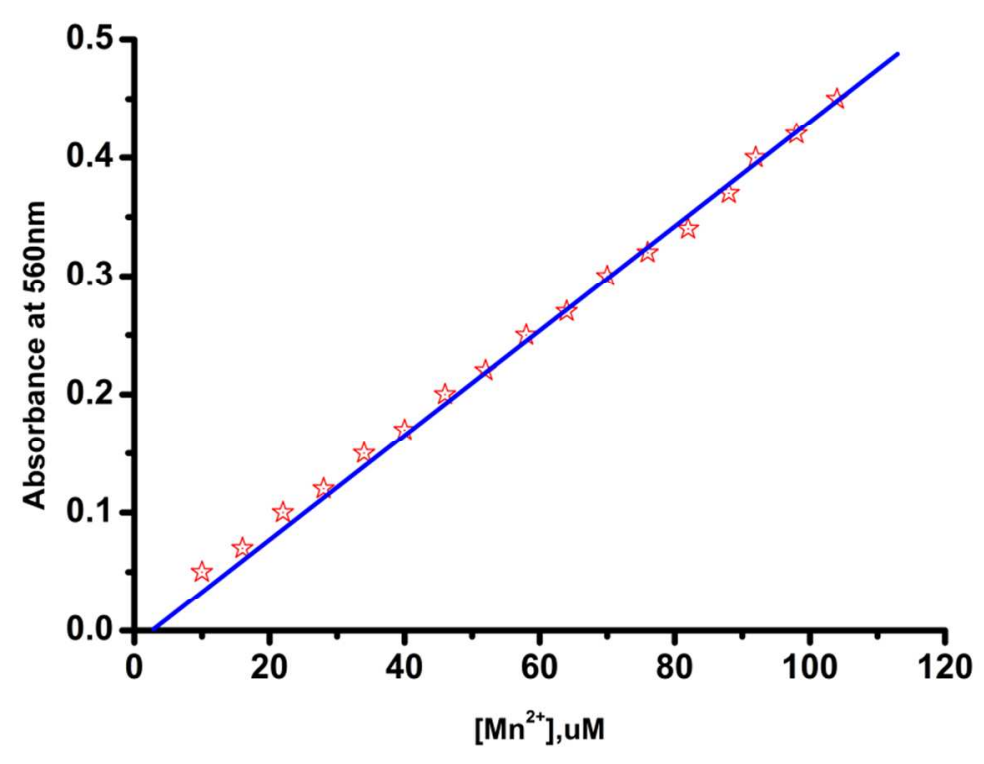

Figure S-22Absorbance vs. $\mathrm{Mn}^{2+}$ concentration of RDDB $(10 \mu \mathrm{M})$ up to $10 \mu \mathrm{M}$ of $\mathrm{Mn}^{2+}$ in acetonitrile.

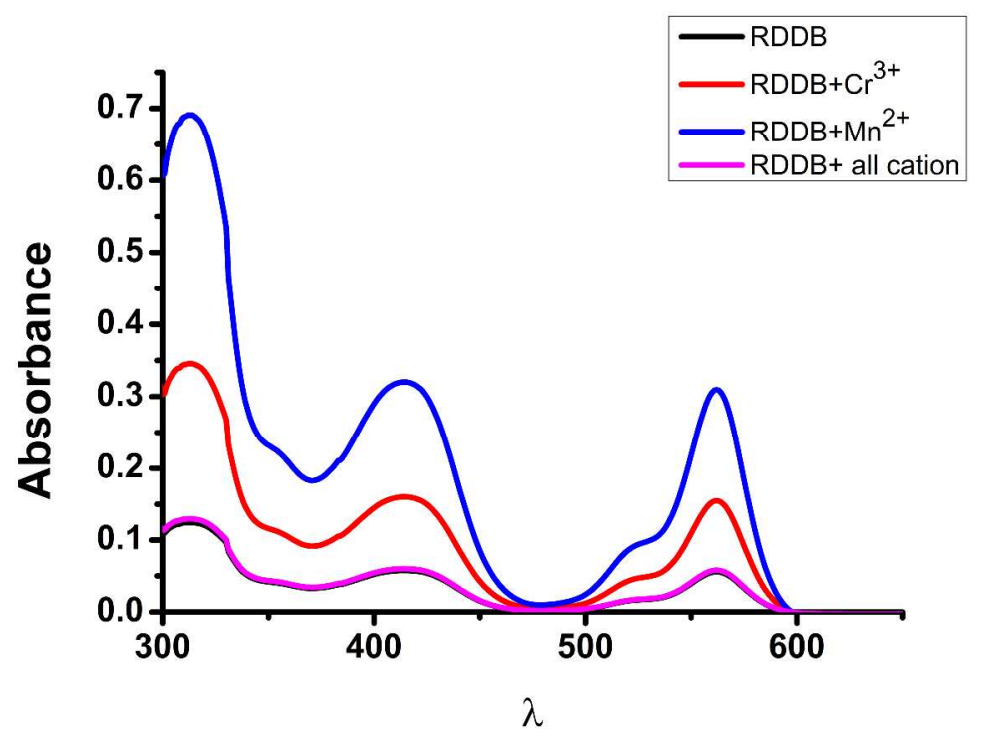

Figure S-23 Plot of absorbance of RDDB $(10 \mu \mathrm{M})$ in presence of different cations $(50 \mu \mathrm{M})$ in acetonitrile. 


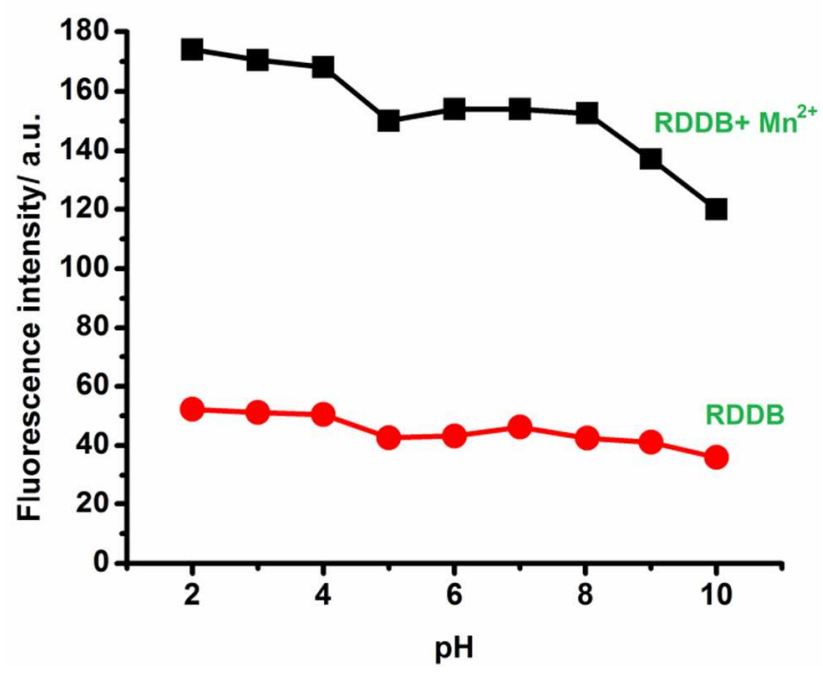

Figure S-24 Effect of $\mathrm{pH}$ on the emission intensity of RDDB(in red line) $(10 \mu \mathrm{M})$ and [RDDB$\left.\mathbf{M n}^{2+}(20 \mu \mathrm{M})\right]$ systems(in black line)in acetonitrile.

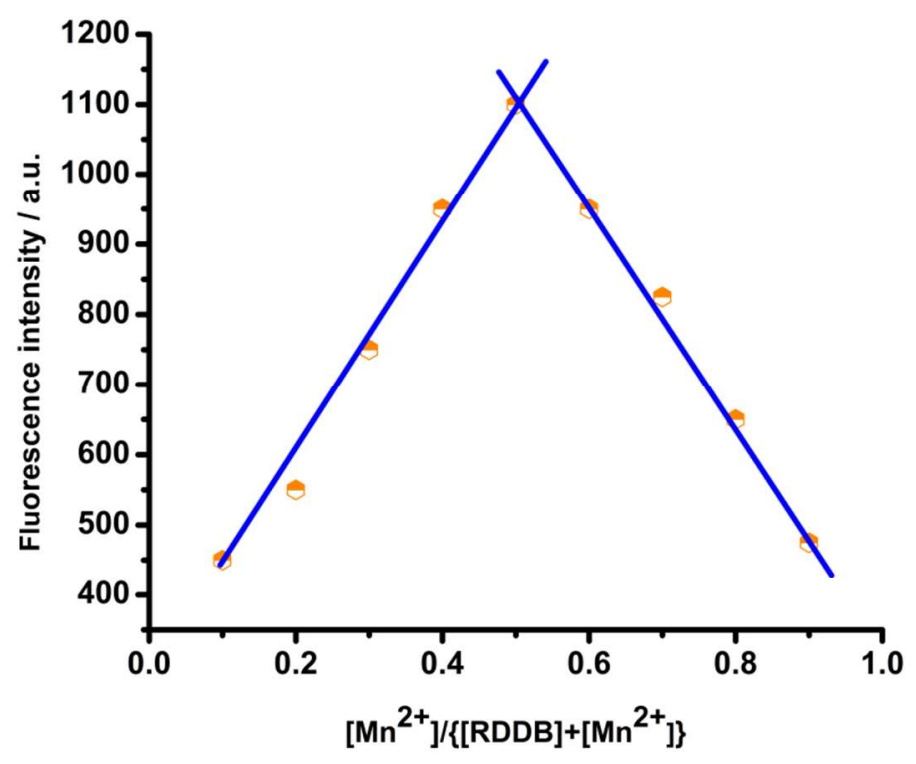

Figure S-25 Job's plot (stoichiometry determination of the RDDB-Mn ${ }^{2+}$ adduct) in acetonitrile. 


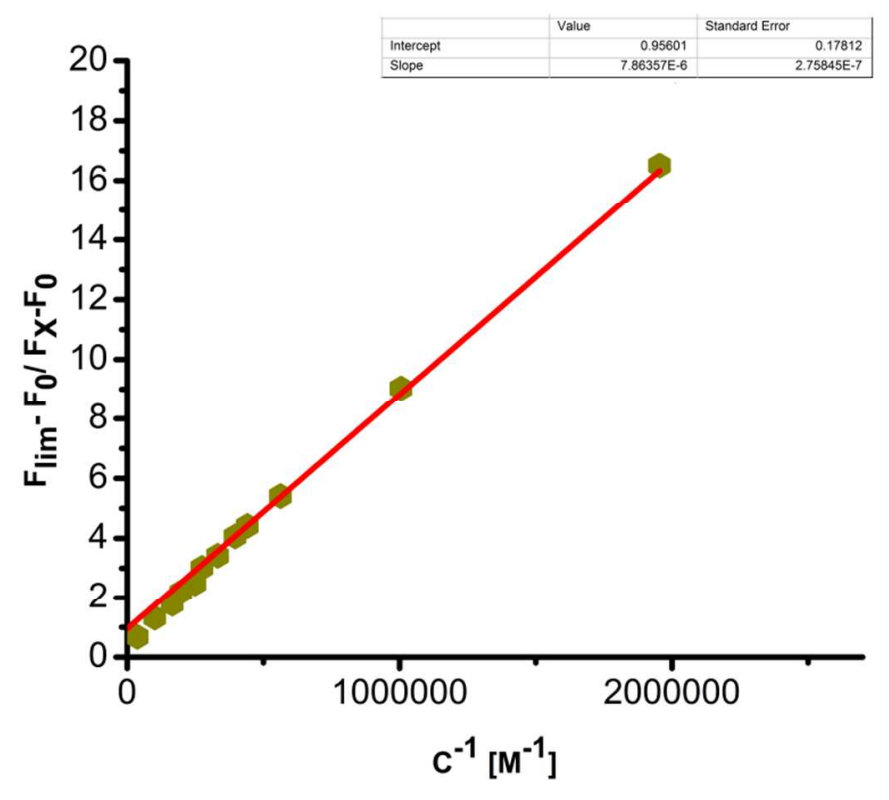

Figure S-26 Determination of the binding constant of RDDB with $\mathrm{Mn}^{2+}$ using the fluorescence technique.

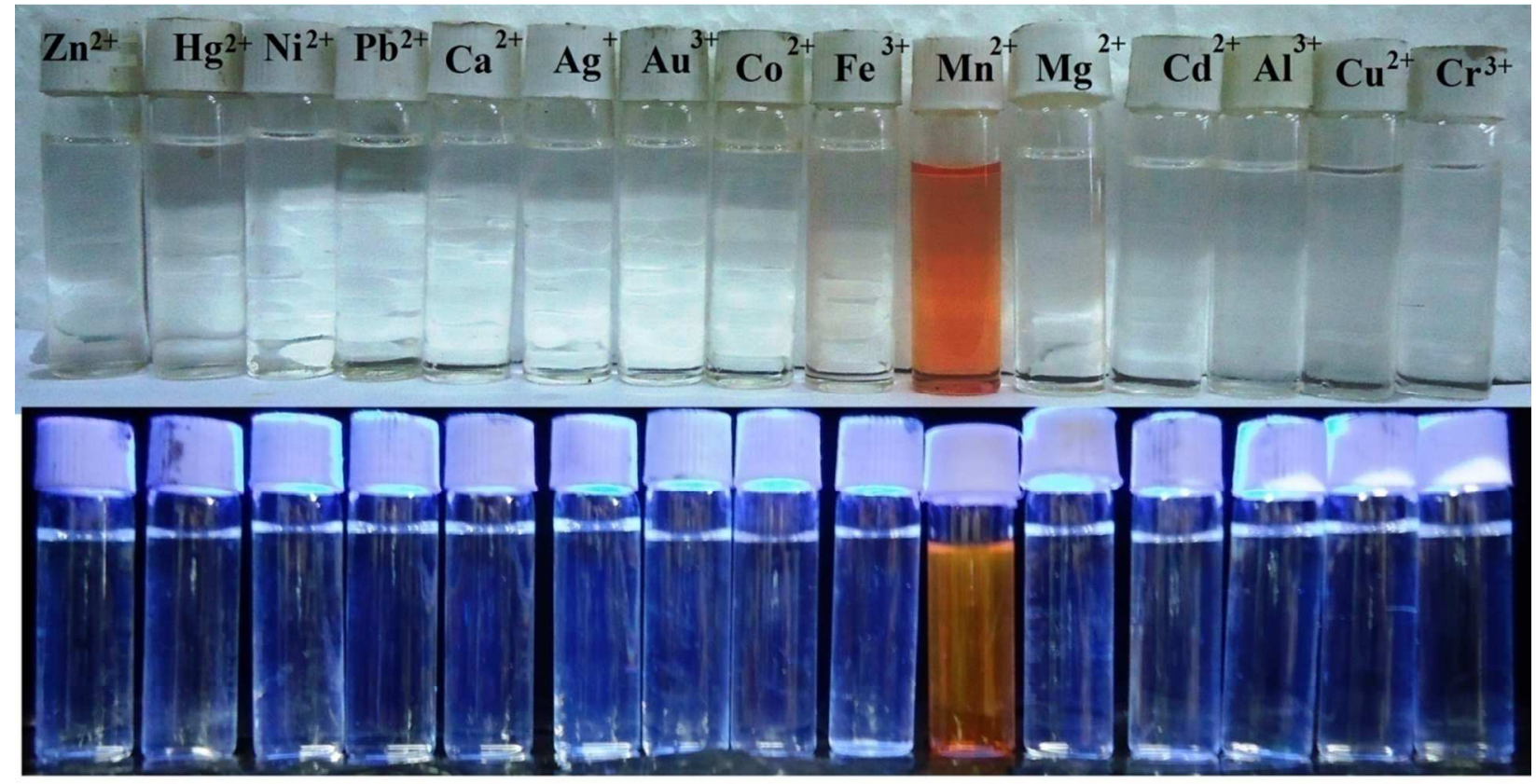

Figure S-27 Color changes (naked eye and under UV-lamp) of RDDB $(10 \mu \mathrm{M})$ in acetonitrile solution upon addition of different cations. 


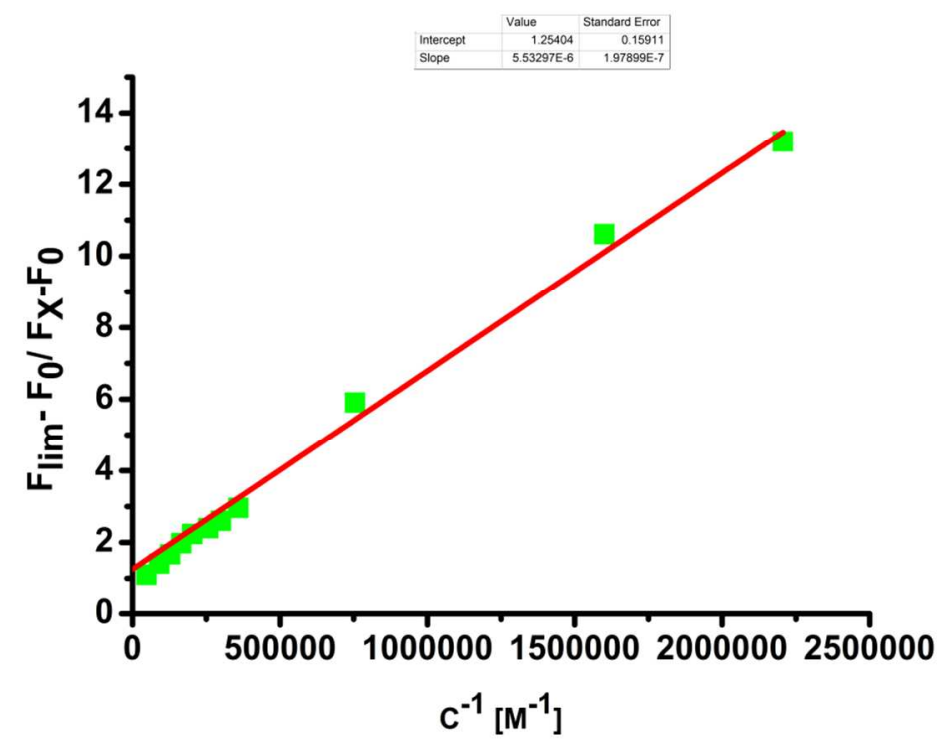

Figure S-28 Determination of the binding constant of FHDB with $\mathrm{Mn}^{2+}$ using the fluorescence technique.

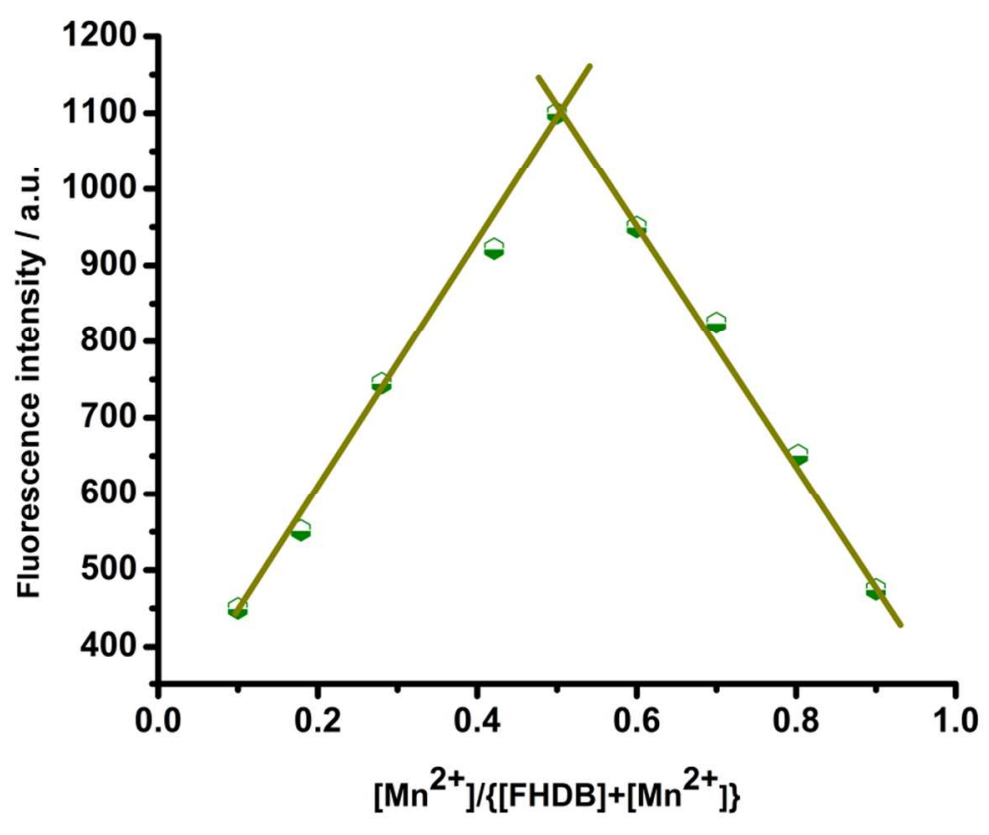

Figure S-29 Job's plot (stoichiometry determination of the FHDB-Mn ${ }^{2+}$ adduct) in DMSO. 


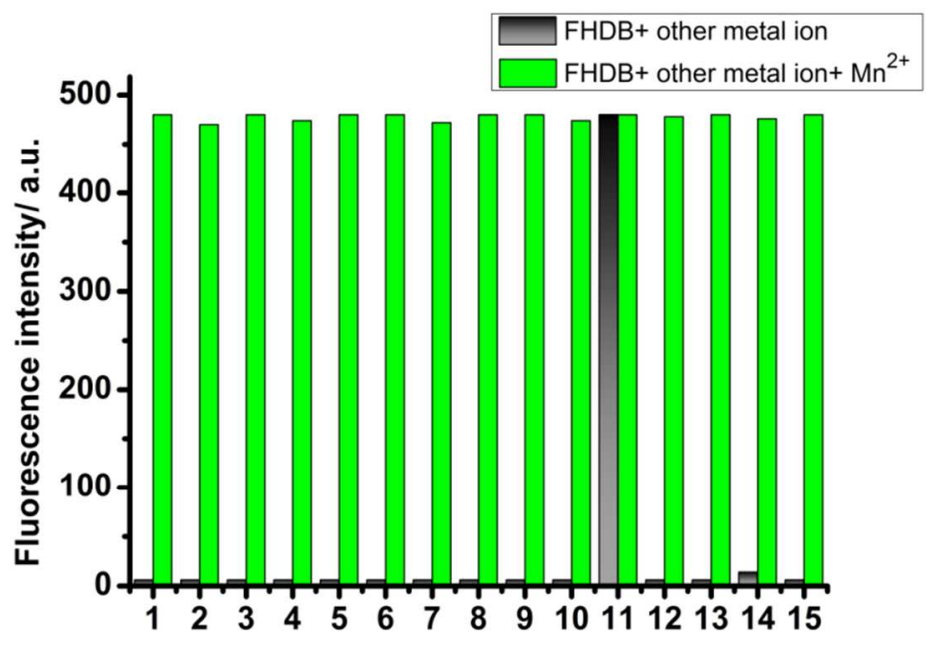

Figure S-30 Plot of emission intensities of FHDB $(10 \mu \mathrm{M})$ in presence of different cations: $\mathrm{Zn}^{2+}$ (1) $\mathrm{Hg}^{2+}(2), \mathrm{Ni}^{2+}(3), \mathrm{Pb}^{2+}(4), \mathrm{Ca}^{2+}(5), \mathrm{Ag}^{+}(6), \mathrm{Au}^{+}(7), \mathrm{Co}^{2+}(8), \mathrm{Fe}^{3+}(9), \mathrm{Mg}^{2+}(10), \mathrm{Mn}^{2+}$ (11), $\mathrm{Cu}^{2+}(12), \mathrm{Cd}^{2+}(13), \mathrm{Cr}^{3+}(14)$ and $\mathrm{Al}^{3+}(15)$.
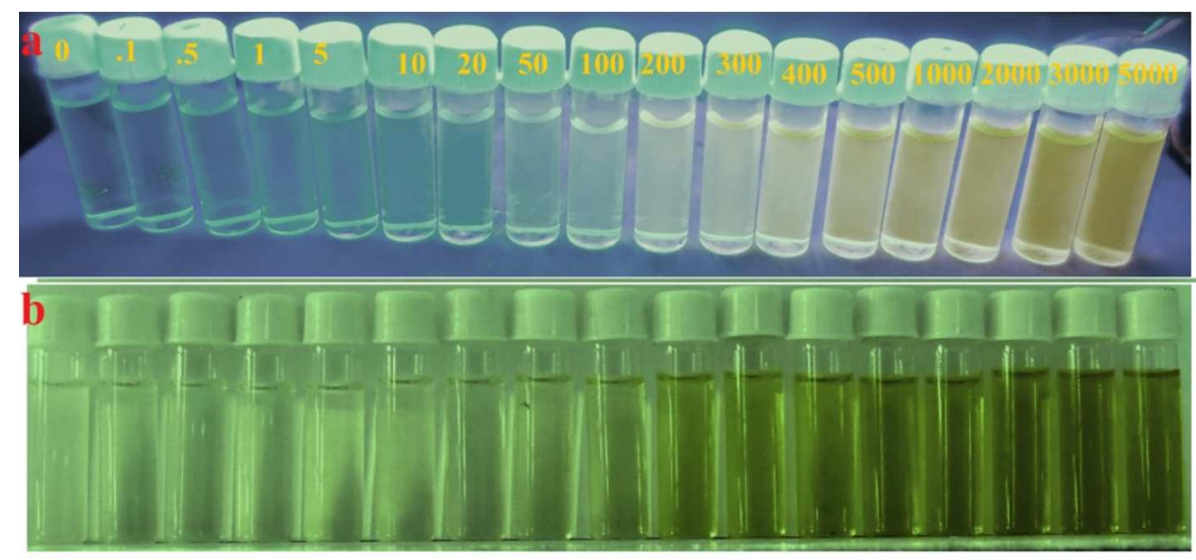

Figure S-31 Color changes of $\mathbf{F H D B}(10 \mu \mathrm{M})$ in DMSO solution upon gradual addition of $\mathrm{Mn}^{2+}$; $(0.0$ to $500.0 \mu \mathrm{M})$ (a) under a hand held UV lamp and (b) necked eye color change in visible light. 


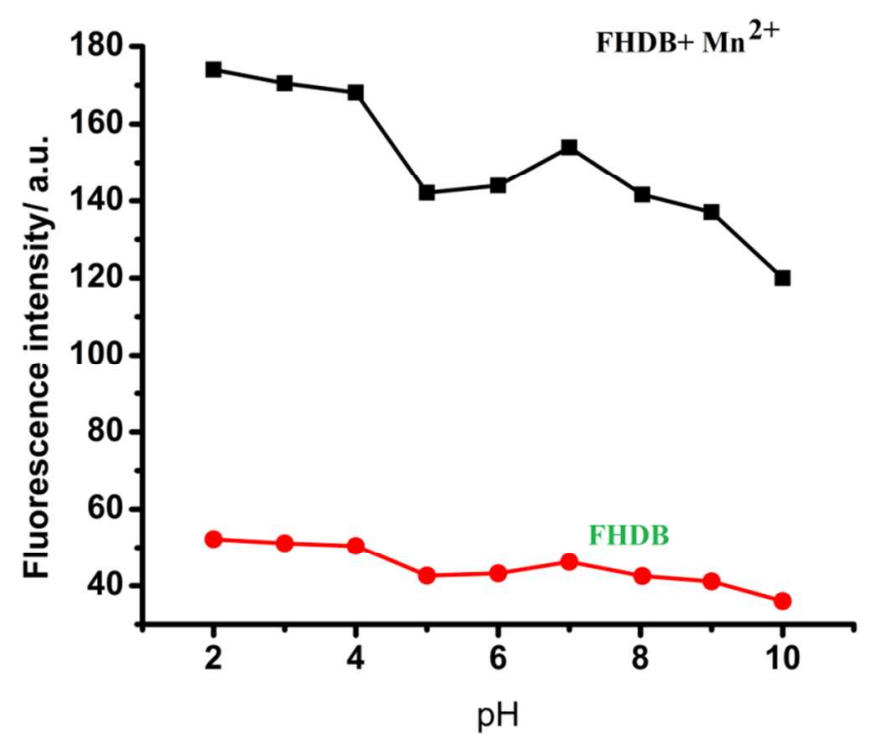

Figure S-32 Effect of $\mathrm{pH}$ on the emission intensity of FHDB (in red line $)(1050 \mu \mathrm{M})$ and $\left[\right.$ FHDB-Mn $\left.{ }^{2+}(20 \mu \mathrm{M})\right]$ systems (in black line)in DMSO.

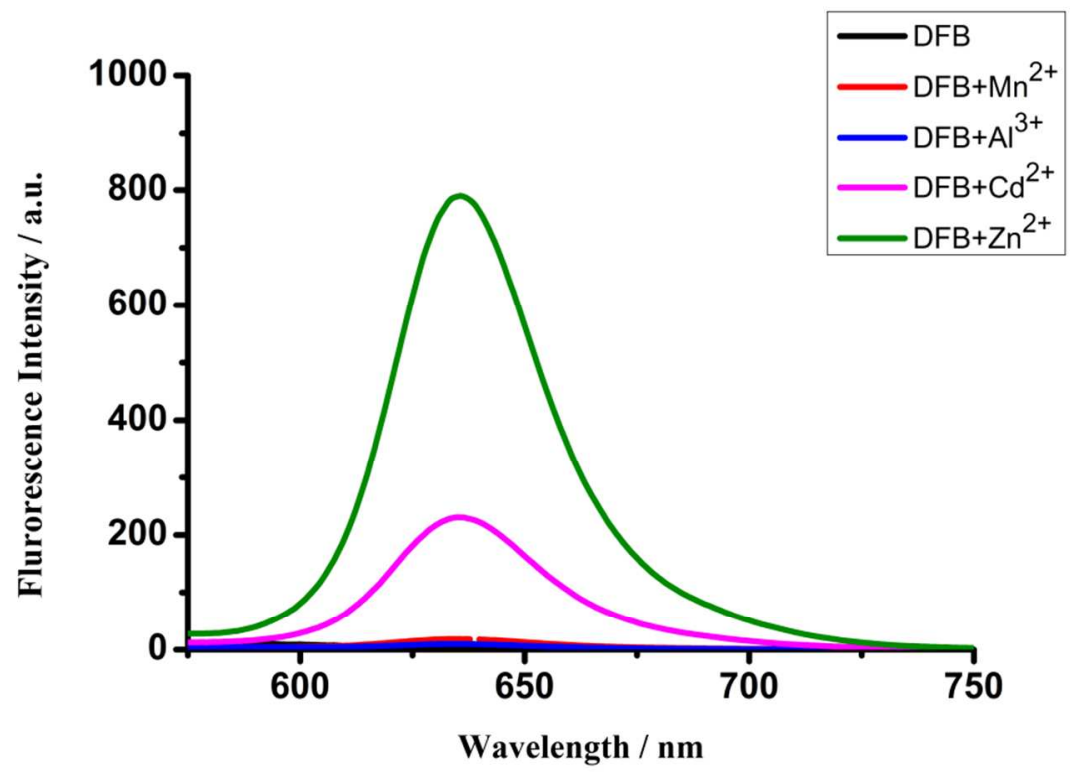

Figure S-33 Emission intensities of DFB $(10 \mu \mathrm{M})$ in presence of different cations $(50 \mu \mathrm{M})$ in $\operatorname{DMSO}\left(\lambda_{\mathrm{ex}}=510 \mathrm{~nm}\right)$. 


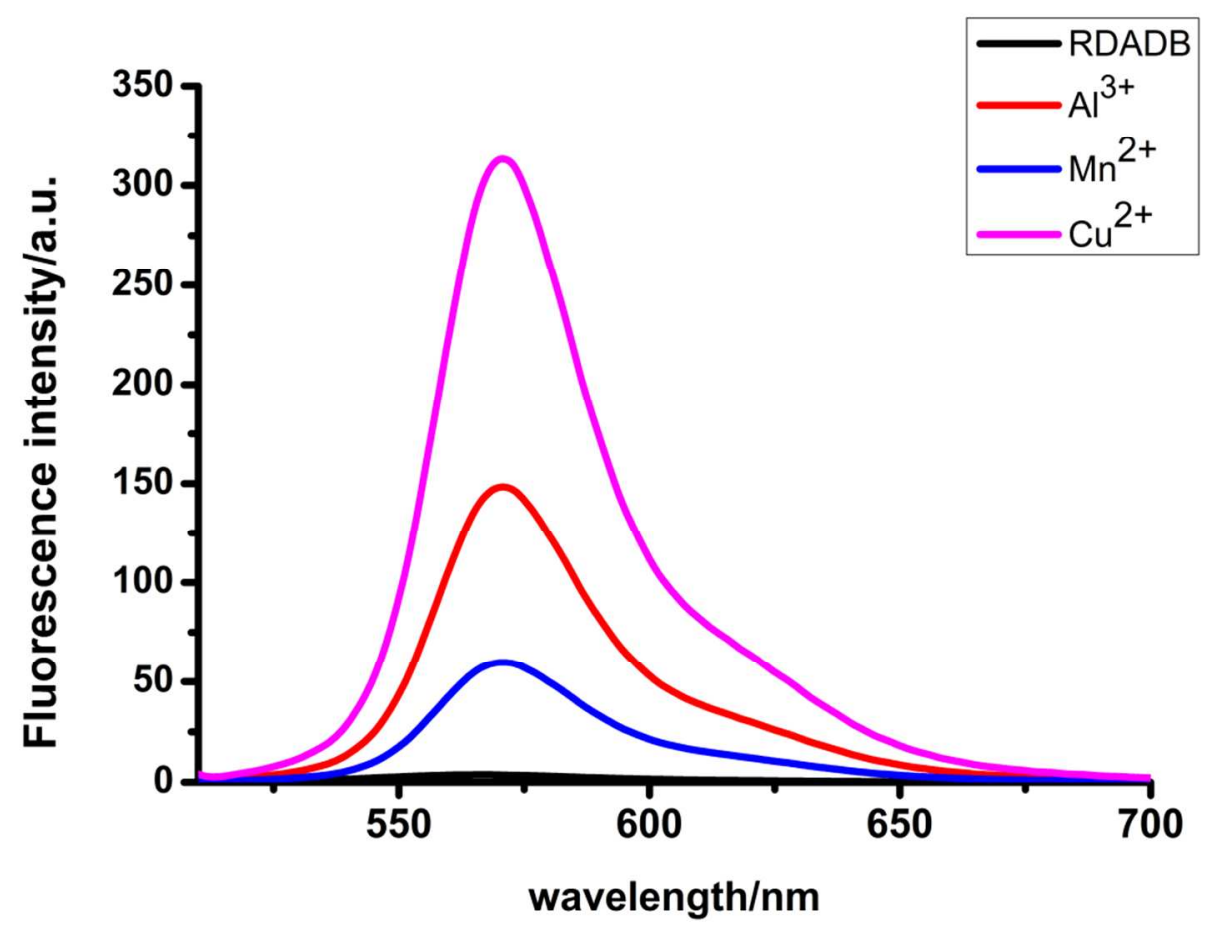

Figure S-34 Emission intensities of RDADB $(10 \mu \mathrm{M})$ in presence of different cations $(50 \mu \mathrm{M})$ in $\operatorname{DMSO}\left(\lambda_{\mathrm{ex}}=520 \mathrm{~nm}\right)$.

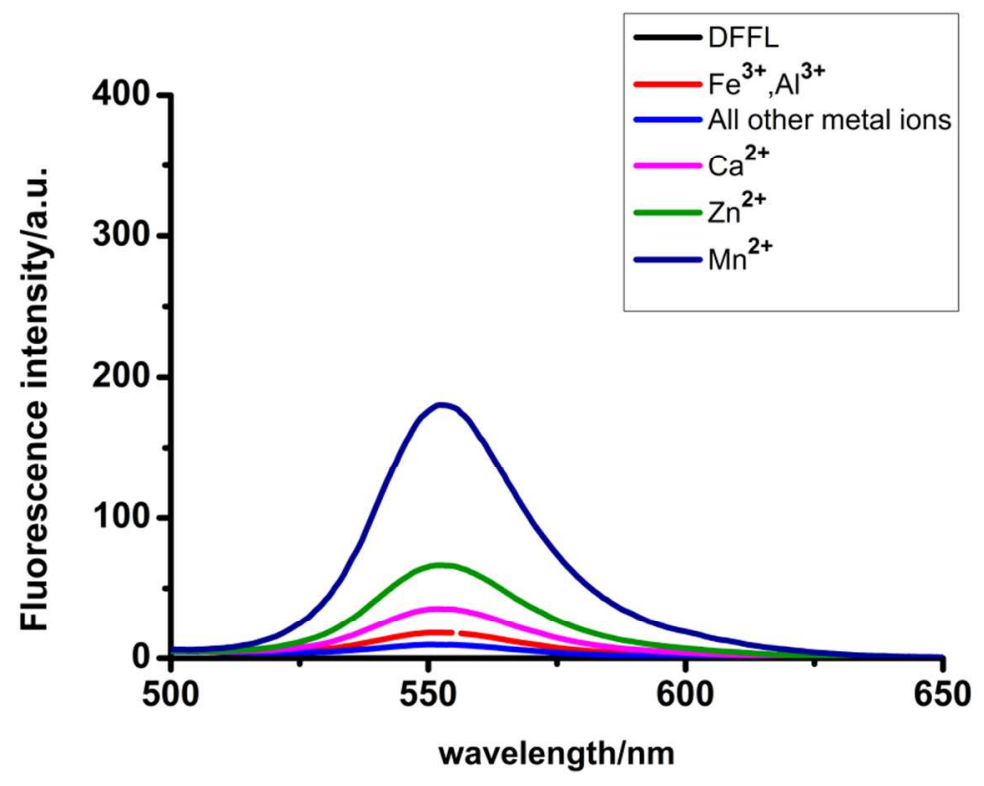

Figure S-35 Emission intensities of DFFL $(10 \mu \mathrm{M})$ in presence of different cations $(50 \mu \mathrm{M})$ in $\operatorname{DMSO}\left(\lambda_{\mathrm{ex}}=500 \mathrm{~nm}\right)$. 


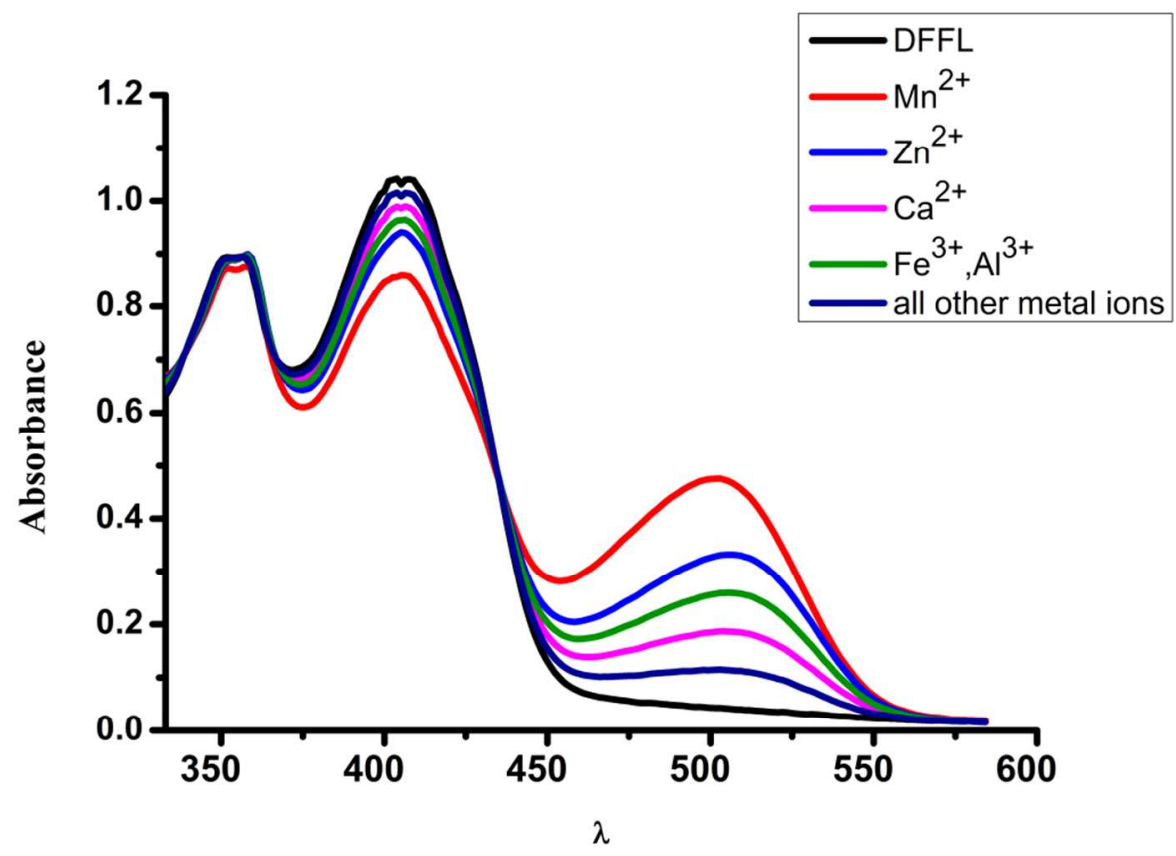

Figure S-36 Absorbance of DFFL $(10 \mu \mathrm{M})$ in presence of different cations $(50 \mu \mathrm{M})$ in DMSO.

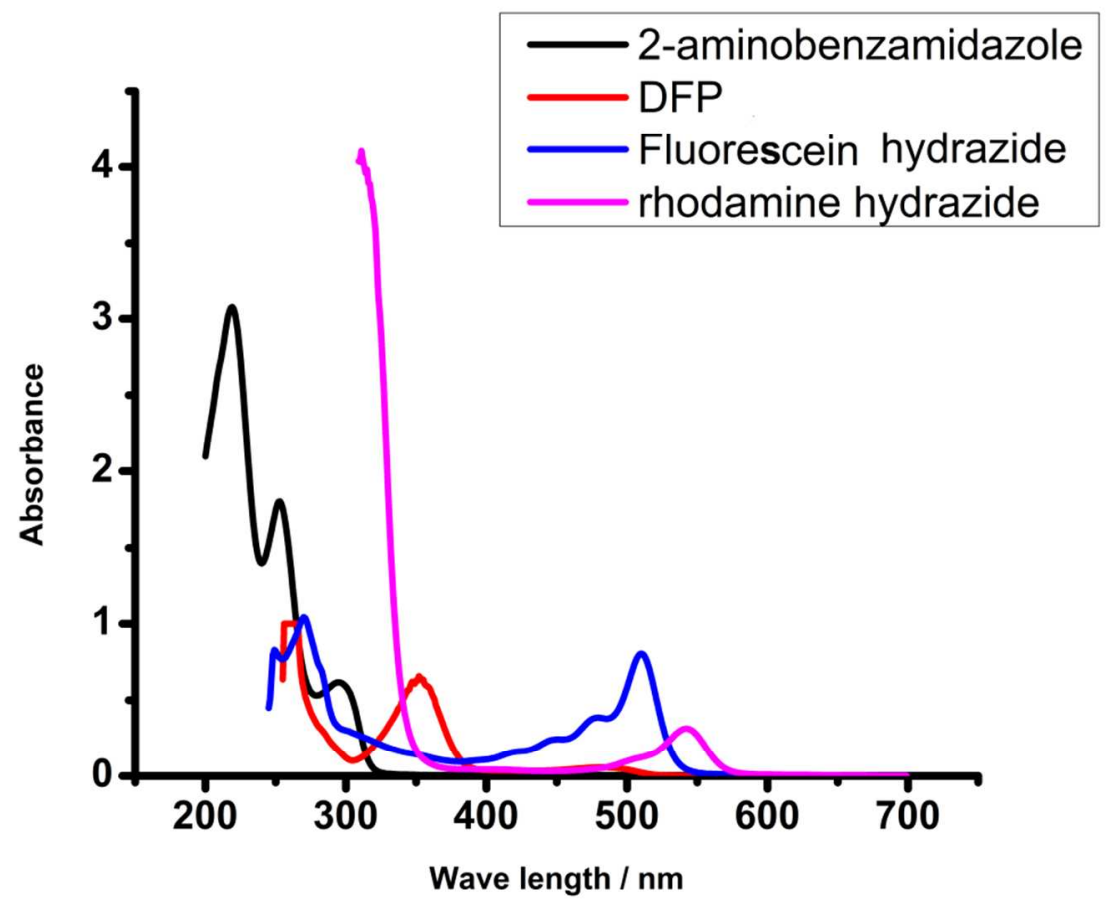

Figure S-37 Relativeabsorbance of DFP, 2-aminobenzamidazole, rhodamine hydrazide and fluorescein hydrazide $(10 \mu \mathrm{M})$ in presence of $\mathrm{Mn}^{2+}(50 \mu \mathrm{M})$ in DMSO. 


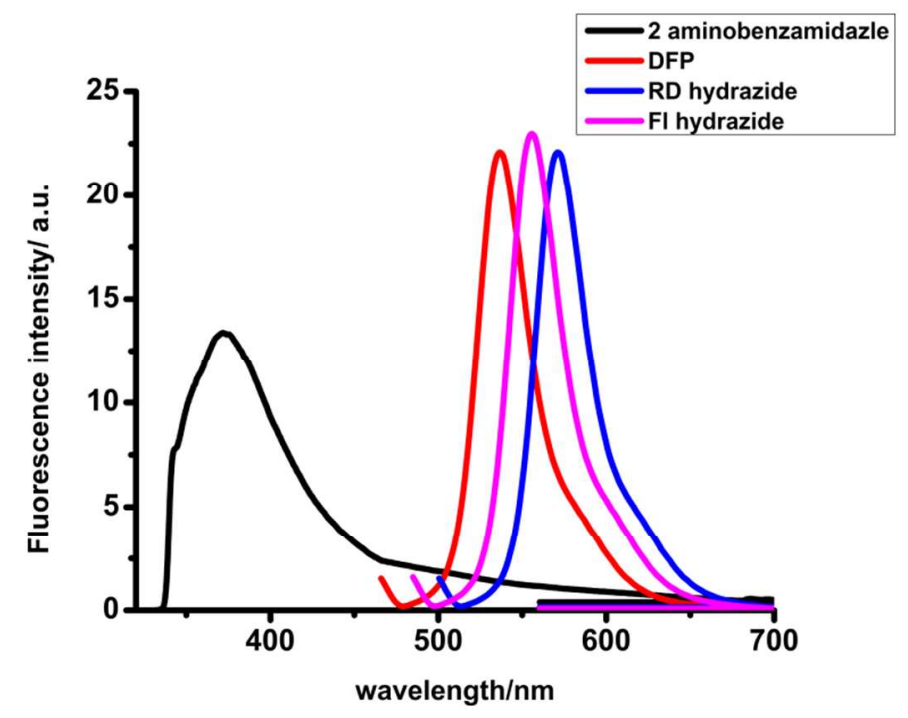

Figure S-38 Relativeemission intensities of DFP, 2-aminobenzamidazole, rhodamine hydrazide and fluorescein hydrazide $(10 \mu \mathrm{M})$ in presence of $\mathrm{Mn}^{2+}(50 \mu \mathrm{M})$ in DMSO.

Table S-1 comparison of individual fluorescence unit and their metal ion binding properties

\begin{tabular}{|c|c|c|c|c|c|c|}
\hline Ligand structures & $\begin{array}{l}\text { UV-Vis } \\
\text { band } \\
\text { (nm) }\end{array}$ & $\begin{array}{l}\text { UV-Vis } \\
\text { band in } \\
\text { presence } \\
\text { of } \mathrm{Mn}^{2+}\end{array}$ & $\begin{array}{l}\text { UV-Vis band } \\
\text { in presence of } \\
\text { other cation } \\
\text { except } \mathrm{Mn}^{2+}\end{array}$ & $\begin{array}{l}\text { Fluores } \\
\text {-cence } \\
\text { bands } \\
\text { (nm) }\end{array}$ & $\begin{array}{c}\text { Fluorescenc } \\
\text {-e band in } \\
\text { presence of } \\
\qquad \mathrm{Mn}^{2+}\end{array}$ & $\begin{array}{l}\text { Fluorescence } \\
\text { bands in } \\
\text { presence of } \\
\text { other cation } \\
\text { except } \mathbf{M n}^{2+}\end{array}$ \\
\hline 1) $-\mathrm{NH}_{2}$ & $\begin{array}{c}286,254 \\
209\end{array}$ & $\begin{array}{c}286,254, \\
209 \\
\text { (quench) }\end{array}$ & $\begin{array}{l}286,254,209 \\
\text { enhances in } \\
\text { presence of } \\
\mathrm{Zn}^{2+}, \mathrm{Al}^{3+}\end{array}$ & 385 & $\begin{array}{c}385 \\
\text { (quench) }\end{array}$ & $\begin{array}{c}385 \text { enhances in } \\
\text { presence of } \mathrm{Zn}^{2+} \text {, } \\
\mathrm{Al}^{3+}\end{array}$ \\
\hline
\end{tabular}




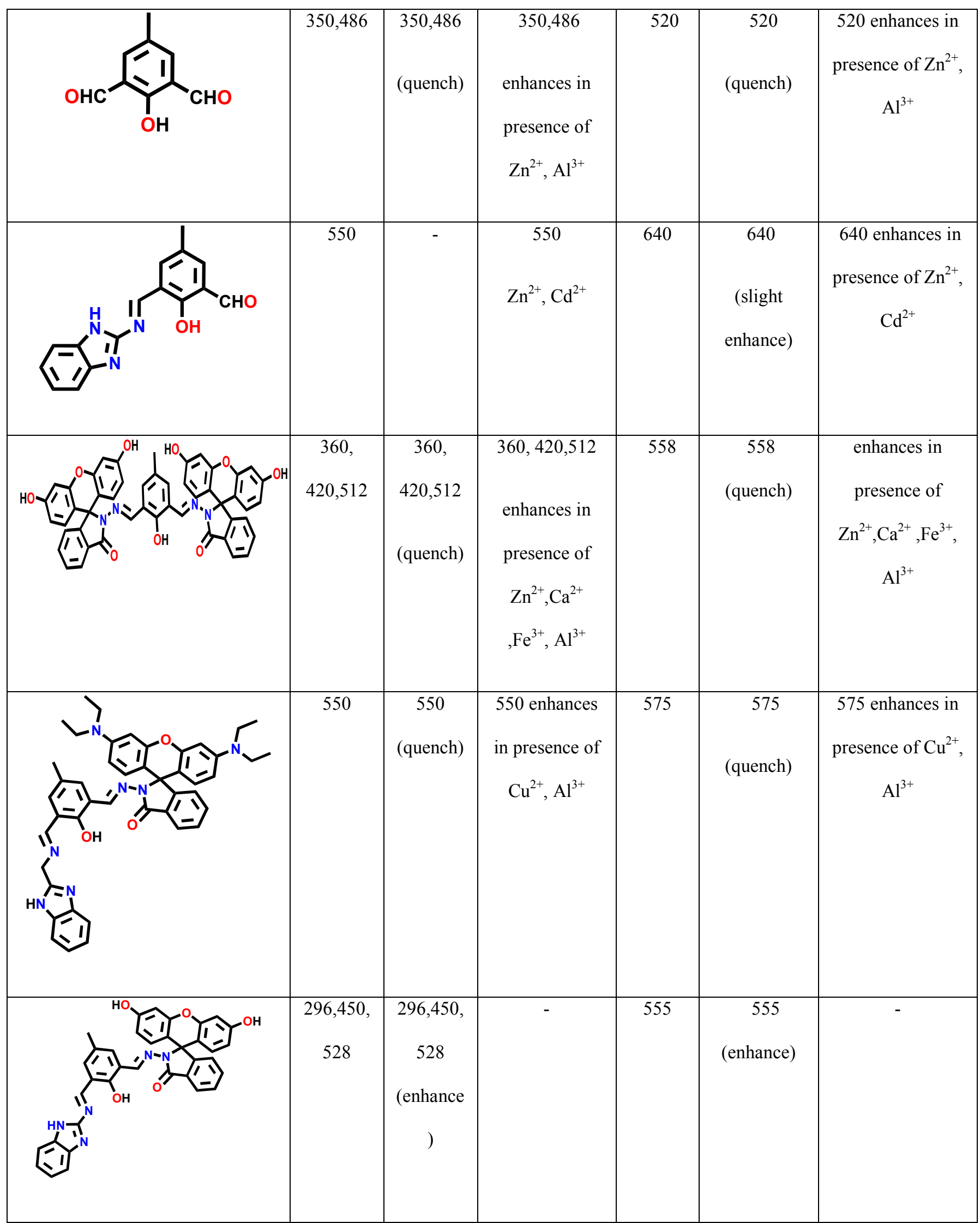




\begin{tabular}{|l|l|l|l|l|l|l|}
\hline 309,412, & 309,412, & $309,412,558$ & 605 & 605 & (enhance) & (slight enhance) \\
\hline
\end{tabular}

Table S-2Comparison of the present probe with existing $\mathrm{Mn}^{2+}$ probes

\begin{tabular}{|c|c|c|c|}
\hline Probe type & Solvent System & LOD & Reference \\
\hline Turn-on & $\begin{array}{c}\mathrm{H}_{2} \mathrm{O} \\
50 \mathrm{~mm} \text { HEPES, } \\
0.1 \mathrm{~m} \mathrm{KNO}_{3}, \mathrm{pH} 7.2\end{array}$ & - & $\begin{array}{l}\text { J. Liang and J. W. Canary, Angew. } \\
\text { Chem. Int. Ed. 2010, 49, 7710- } \\
\text { 7713. }\end{array}$ \\
\hline $\begin{array}{l}\text { Turn-on ,Metal ion } \\
\text { displacement }\end{array}$ & 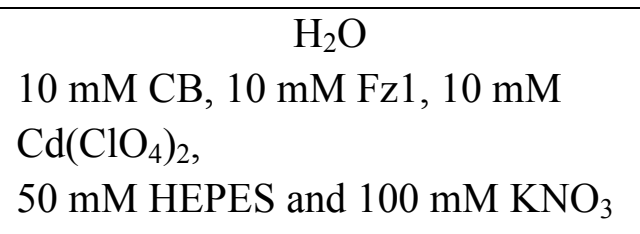 & - & $\begin{array}{l}\text { Gruppi, F.; Liang, J.; Bartelle, B. } \\
\text { B.; Royzen, M.; Turnbull, D. H.; } \\
\text { Canary, J. W. Chem. Commun. } \\
\text { 2012, 48, 10778-10780. }\end{array}$ \\
\hline $\begin{array}{l}\text { Turned on } \\
\text { (surface of graphene } \\
\text { nanosheets) }\end{array}$ & $\mathrm{H}_{2} \mathrm{O}$ & $4.6 \times 10^{-5} \mathrm{M}$ & $\begin{array}{l}\text { Mao, X.; Su, H.; Tian, D.; Li, H.; } \\
\text { Yang, R. ACS Appl. Mater. } \\
\text { Interfaces2013, 5, 592-597. }\end{array}$ \\
\hline Turn-on & DMF & $1.5 \times 10^{-5} \mathrm{molL}^{-1}$ & $\begin{array}{l}\text { Kaya, I.; Yildirim, M.; Kamaci, M. } \\
\text { Synth. Met. 2011, 161, 2036-2040. }\end{array}$ \\
\hline colorimeric & DMF & $6.03 \mu \mathrm{M}$ & $\begin{array}{l}\text { Lee, Y. J.; Lim, C.; Suh, H.; Song, } \\
\text { E. J.; Kim, C. Sens. Actuators, B } \\
\text { 2014, 201, 535-544. }\end{array}$ \\
\hline Turn-on & Methanol & - & $\begin{array}{l}\text { Jali, B. R.; Masud, K.; Baruah, J. } \\
\text { B. Polyhedron 2013, 51, 75-81. }\end{array}$ \\
\hline Turn-on & Methanol & - & $\begin{array}{l}\text { Pathak, R. K.; Dessingou, J.; Rao, } \\
\text { C. P. Anal. Chem. 2012, 84, 8294- } \\
\text { 8300. }\end{array}$ \\
\hline Turned on & $\mathrm{CH}_{3} \mathrm{CN}$ & - & $\begin{array}{l}\text { Bakthavatsalam, S.; Sarkar, A.; } \\
\text { Rakshit, A.; Jain, S.; Kumar, A.; }\end{array}$ \\
\hline
\end{tabular}




\begin{tabular}{|l|c|c|l|}
\hline & & & $\begin{array}{l}\text { Datta,A. Chem. Commun. 2015, } \\
51,2605-2608 .\end{array}$ \\
\hline Turned on & $1: 1(\mathrm{v} / \mathrm{v}) \mathrm{CH}_{3} \mathrm{CN}: \mathrm{H}_{2} \mathrm{O}(\mathrm{pH} 4.0)$ & - & $\begin{array}{l}\text { Dutta, K.; Deka, R. C.; Das, D. K. } \\
\text { J. Fluoresc. 2013, 23, 1173-1178. }\end{array}$ \\
\hline $\begin{array}{l}\text { surface Plasmon } \\
\text { resonance (SPR) } \\
\text { absorption }\end{array}$ & - & $0.1 \mu \mathrm{M}$ & $\begin{array}{l}\text { Gaoa, Y.; Xina, J.; Shena, Z.; } \\
\text { Panb, W.; Li, X.; Wua, A. Sens. } \\
\text { Actuators, B 2013, 181, 288-293. }\end{array}$ \\
\hline $\begin{array}{l}\text { Turned on, } \\
\text { colorimetric }\end{array}$ & $\begin{array}{l}99: 1(\mathrm{v} / \mathrm{v}) \text { acetonitrile-HEPES }(10 \mu \mathrm{M}, \\
\mathrm{pH}=7.4)\end{array}$ & $5 \times 10^{-8} \mathrm{M}$ & Present work \\
\hline
\end{tabular}

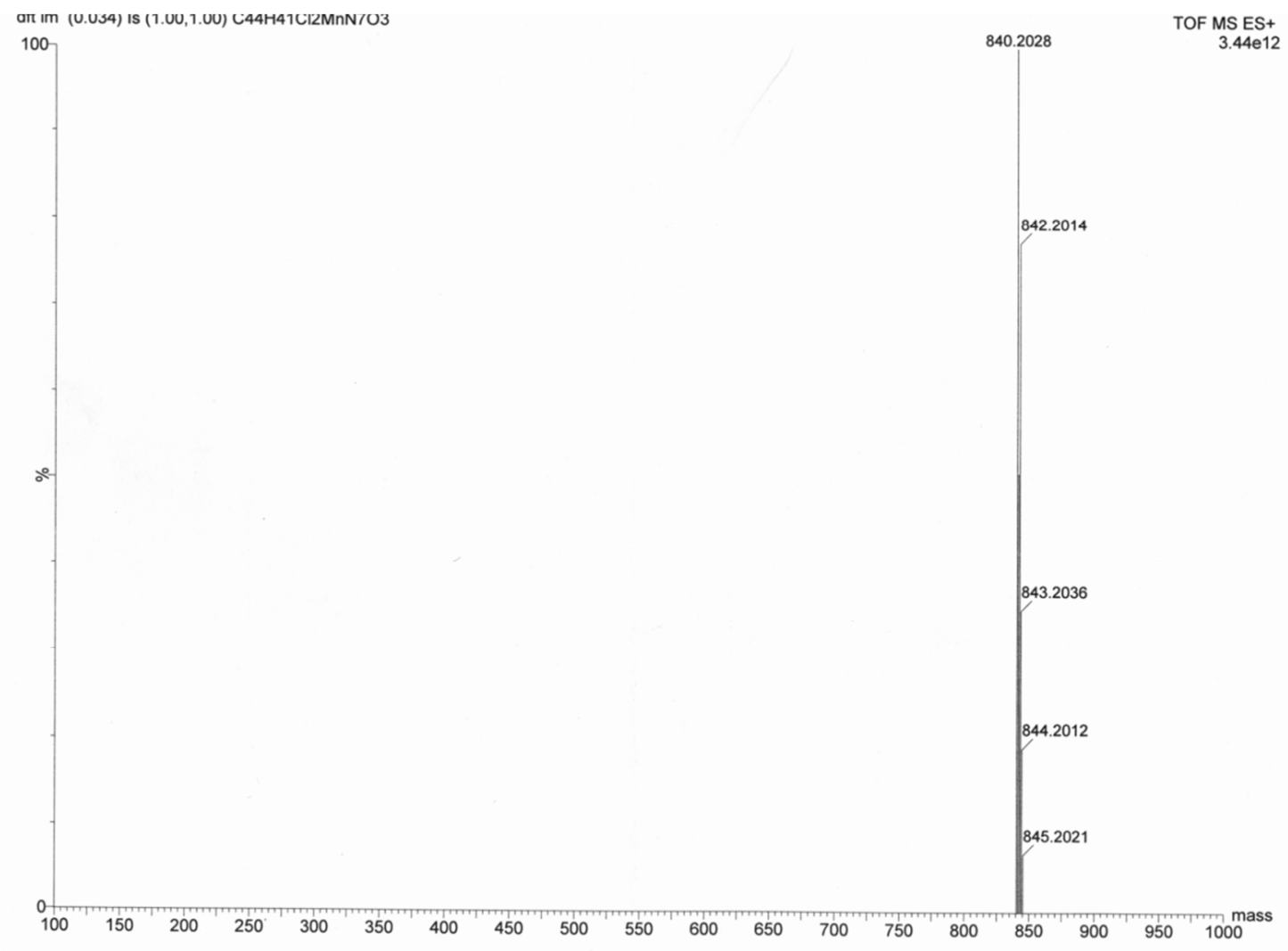

Figure S-39QTOF MASS spectrum of $\left[\right.$ RDDB-Mn $\left.{ }^{2+}\right]$ system. 


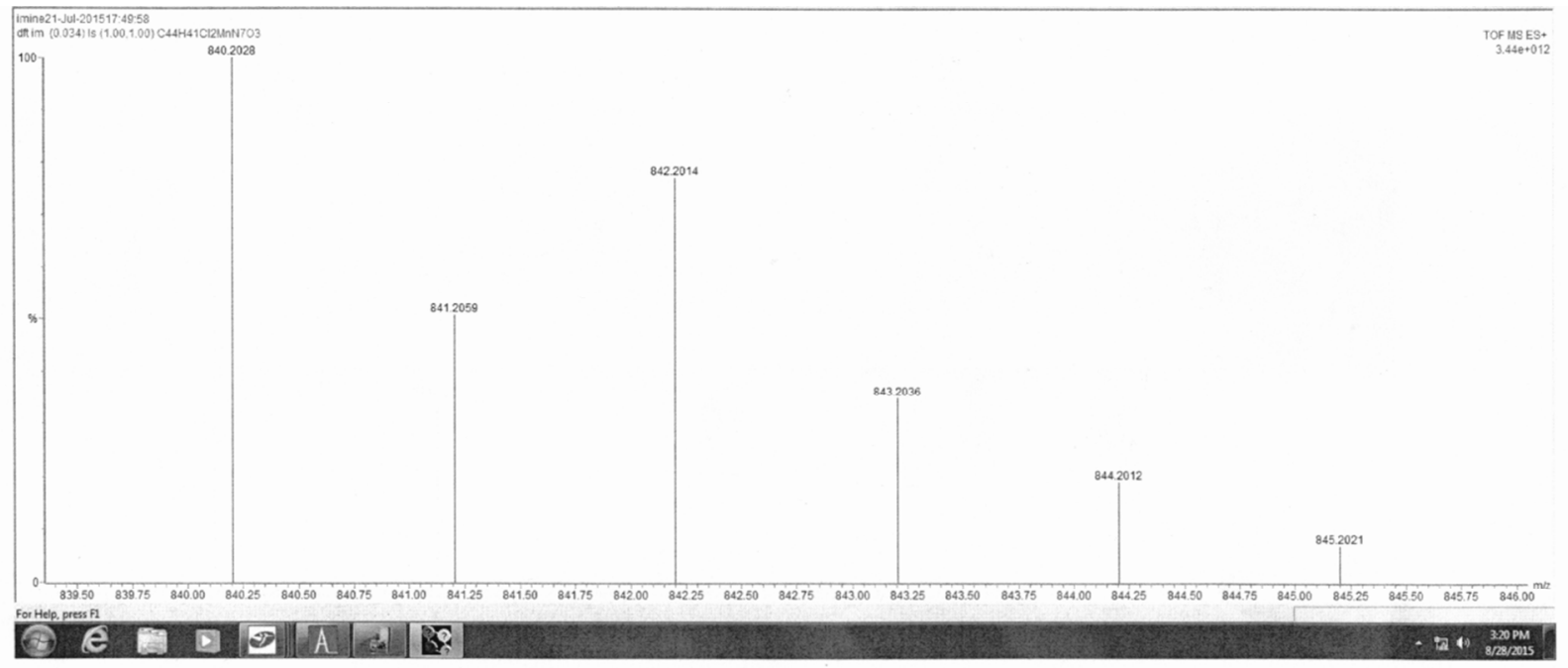

Figure S-40 Expanded QTOF MASS spectrum of [RDDB-Mn ${ }^{\mathbf{2 +}}$ ] system.

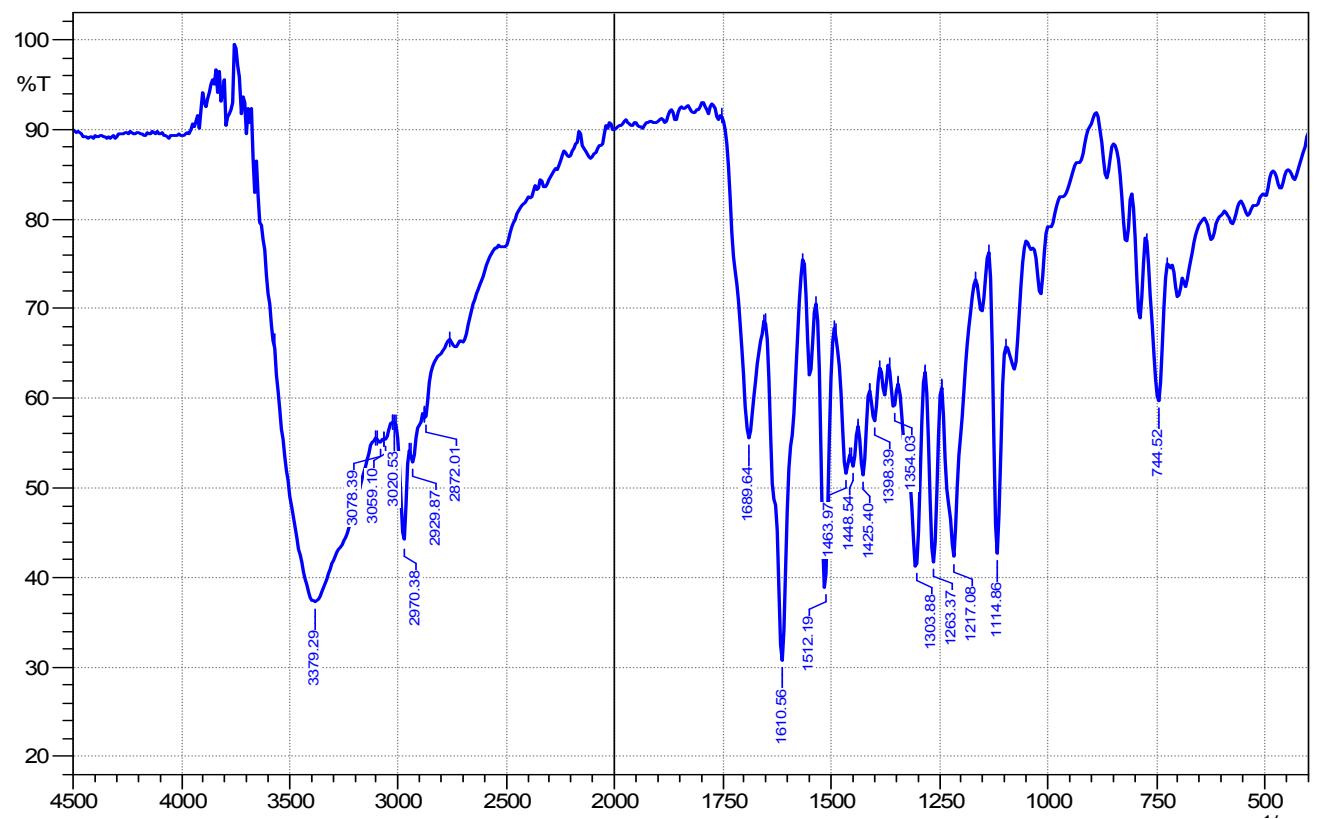

Figure S-41FTIR complex of RDDB. 


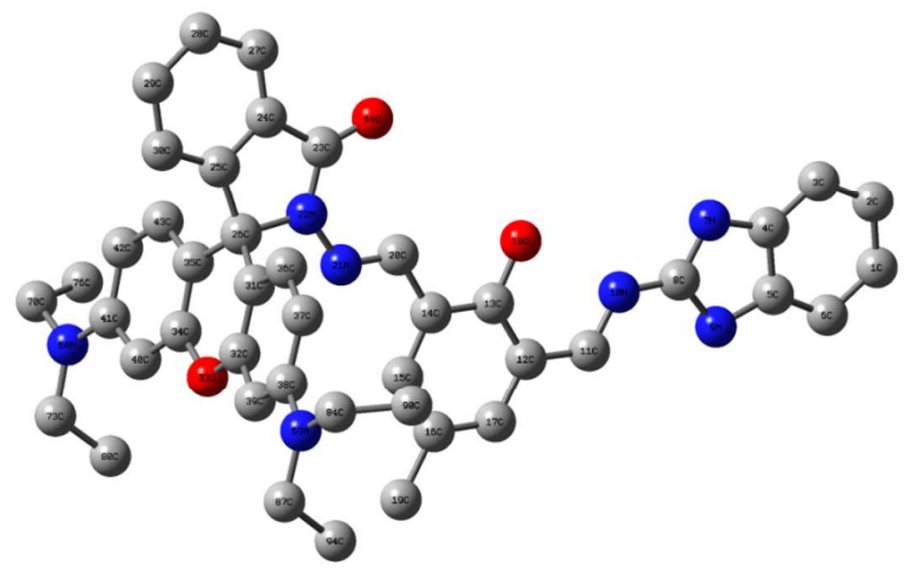

Figure S-42 Energy optimized geometry of RDDB.

Table S-3 Frontier molecular orbitals (MOs) of RDDB and the energy levels of the MOs are shown (in a.u). Calculations are based on ground state geometry by DFT at the B3LYP/6-31G (d)/level using Gaussian 09.

\begin{tabular}{|c|c|c|}
\hline Frontier orbital & Energy (a.u.) & Energy optimised geometry \\
\hline LUMO+1 & -0.0473 & \\
\hline LUMO & -0.0779 & \\
\hline
\end{tabular}



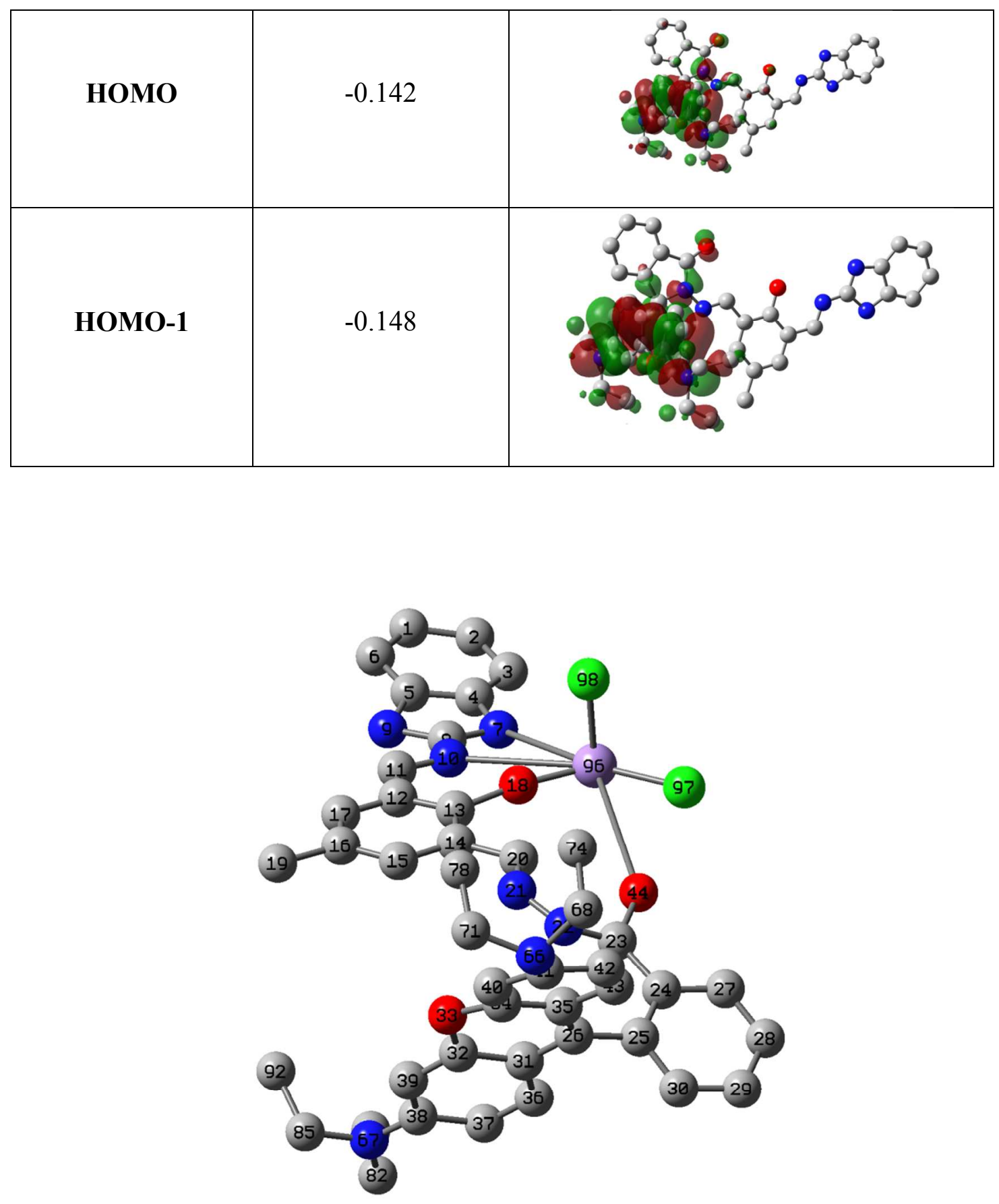

Figure S-43 Energy optimized geometry of RDDB- $\mathrm{Mn}^{2+}$. 
Table S-4The frontier molecular orbitals (MOs) of RDDB-Mn ${ }^{2+}$ and the energy levels of the MOs are shown (in a.u). Calculations are based on ground state geometry by DFT at the B3LYP/LANL2DZ level.

\begin{tabular}{|c|c|c|}
\hline Frontier orbital & Energy (a.u.) & Energy optimised geometry \\
\hline LUMO+1 & -0.067 & \\
\hline LUMO & -0.073 & \\
\hline HOMO & -0.115 & \\
\hline HOMO-1 & -0.122 & \\
\hline
\end{tabular}




\section{In vitro cell imaging}

RAW264.7 cells were cultured in Dulbecco's modified eagle medium (DMEM) supplemented with $10 \%$ fetal bovine serum (FBS) and $1 \%$ penicillin/streptomycin at $37^{\circ} \mathrm{C}$ and $5 \% \mathrm{CO}_{2}$. For in vitro imaging studies, the cells are seeded in 6-well tissue culture plates with a seeding density of $10^{5}$ cells per well. After reaching $60 \%-70 \%$ confluence, the previous DMEM medium was replaced with serum free DMEM medium, supplemented with $20 \mu \mathrm{M}$ of RDDB and incubated for $2 \mathrm{~h}$. Then cells were washed three times with PBS buffer to remove extracellular RDDB. Then $\mathrm{Mn}^{2+}(50 \mu \mathrm{M})$ was added into the medium and then further incubated for $3 \mathrm{~h}$ to facilitate metal ion uptake by cells. After washing with PBS buffer, images of live cells were taken by Olympus IX81 microscope. Differential interference contrast (DIC) and fluorescence images of live cells were obtained by Olympus IX81 microscope using image-pro plus version 7.0 software.

\section{Cytotoxicity assay}

In vitro cytotoxicity was measured by using the colorimetric methyl thiazolyl tetrazolium (MTT) assay against RAW264.7cells. Cells were seeded into 24-well tissue culture plate in presence of $500 \mu \mathrm{L}$ Dulbecco's modified eagle medium (DMEM) supplemented with $10 \%$ fetal bovine serum (FBS) and $1 \%$ penicillin/streptomycin at $37{ }^{\circ} \mathrm{C}$ temperature and $5 \% \mathrm{CO}_{2}$ atmosphere for overnight and then incubated for 12 hours in presence of RDDBat different concentrations (10$100 \mu \mathrm{M})$. Then cells were washed with PBS buffer and $500 \mu \mathrm{L}$ supplemented DMEM medium was added. Subsequently, $50 \mu \mathrm{L}$ 3-(4,5-dimethylthiazol-2-yl)-2,5-diphenyltetrazolium bromide MTT $(5 \mathrm{mg} / \mathrm{mL})$ was added to each well and incubated for 4 hours.Next, violet formazan was dissolved in $500 \mu \mathrm{L}$ of sodium dodecyl sulfate solution in water/DMFmixture. The absorbance of 
solution was measured at $570 \mathrm{~nm}$ using microplate reader. The cell viability was determined by assuming $100 \%$ cell viability for cells without RDDB.

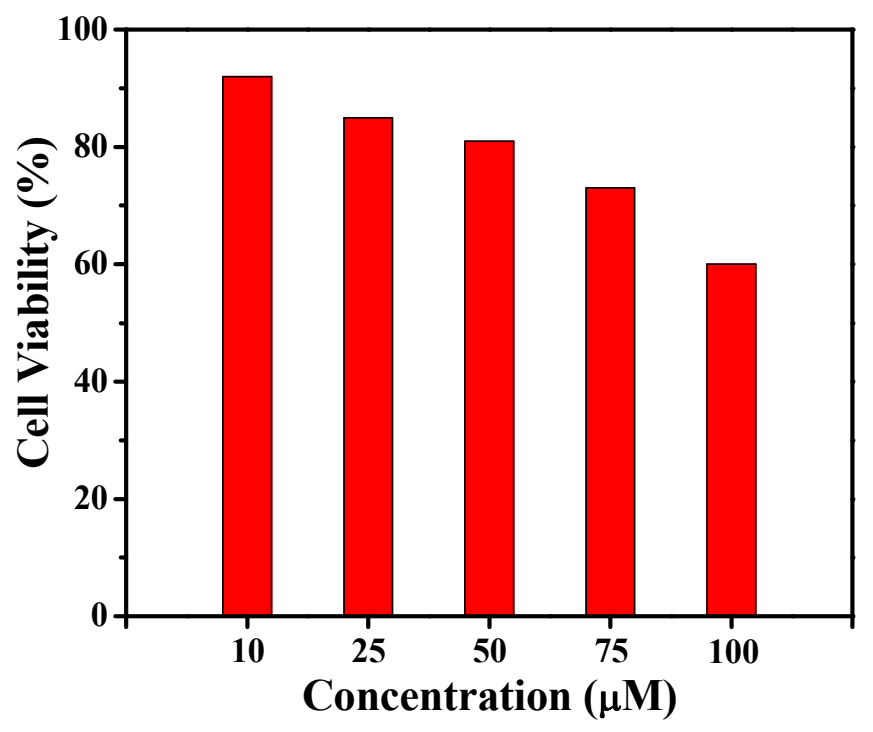

Figure S-44 Cell viability of RDDB at different concentration against RAW264.7 cells after 12 hours incubation. 